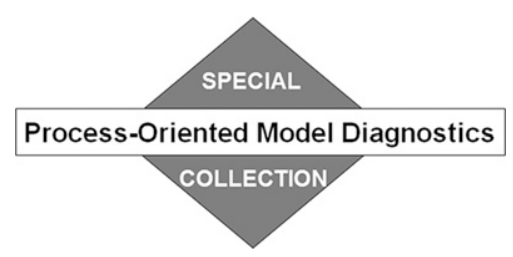

\title{
Impact of Dynamically Downscaling Two CMIP5 Models on the Historical and Future Changes in Winter Extratropical Cyclones along the East Coast of North America
}

\author{
ZHENHAI ZHANG \\ Center for Western Weather and Water Extremes, Scripps Institution of Oceanography, \\ University of California, San Diego, La Jolla, California \\ BRIAN A. COLLE \\ School of Marine and Atmospheric Sciences, Stony Brook University, State University of New York, \\ Stony Brook, New York
}

(Manuscript received 25 March 2018, in final form 20 July 2018)

\begin{abstract}
This study investigates the impact of dynamical downscaling on historical and future projections of winter extratropical cyclones over eastern North America and the western Atlantic Ocean. Six-hourly output from two global circulation models (GCMs), CCSM4 and GFDL-ESM2M, from phase 5 of the Coupled Model Intercomparison Project (CMIP5) are used to create the initial and boundary conditions for 20 historical (1986-2005) and 20 future (2080-99) winter simulations using the Weather Research and Forecasting (WRF) Model. Two sets of WRF grid spacing $\left(1.0^{\circ}\right.$ and $\left.0.2^{\circ}\right)$ are examined to determine the impact of model resolution. Although the cyclone frequency in the WRF runs is largely determined by the GCM predictions, the higher-resolution WRF reduces the underprediction in cyclone intensity. There is an increase in late-twentyfirst-century cyclone activity over the east coast of North America in CCSM4 and its WRF, whereas there is little change in GFDL-ESM2M and WRF given that there is a larger decrease in the temperature gradient in this region. There is a future increase in relatively deep cyclones over the East Coast in the high-resolution WRF forced by CCSM4. These storms are weaker than the historical cases early in their life cycle, but then because of latent heating they rapidly develop and become stronger than the historical events. This increase does not occur in the low-resolution WRF or the high-resolution WRF forced by GFDL since the latent heat increase is relatively small. This implies that the diabatic processes during cyclogenesis may become more important in a warmer climate, and these processes may be too weak in existing coarse-resolution GCMs.
\end{abstract}

\section{Introduction}

\section{a. Background}

Extratropical cyclones often produce heavy precipitation and strong surface winds (Field and Wood 2007; Knox et al. 2011; Naud et al. 2012; Zheng et al. 2017) as well as inland flooding (Colle 2003) and storm surge (Colle et al. 2008, 2010; Sweet and Zervas 2011; Catalano and Broccoli 2018). Recently, there has been growing interest in assessing the future changes of the extratropical cyclones, especially over highly populated regions, such as the east coast of North America. For example, sea level rise in the next 50-100 years would

Corresponding author: Dr. Brian A. Colle, brian.colle@ stonybrook.edu result in many more coastal flood events even if the frequency and intensity of storms do not change (Roberts et al. 2017; Orton et al. 2016).

Several studies have highlighted a decrease in the winter extratropical cyclone frequency over the North Hemisphere during the later twenty-first century in global circulation models (GCMs) that is due to decreasing low-level baroclinicity (Geng and Sugi 2003; Lambert and Fyfe 2006; Bengtsson et al. 2006; Chang 2013; Zappa et al. 2013; Tamarin-Brodsky and Kaspi 2017). However, there are large uncertainties among different GCMs. Chang (2013) found that the mean

Publisher's Note: This article was revised on 18 December 2018 to include the designation that it belongs to the Process-Oriented Model Diagnostics special collection. 
frequency change of significant cyclones (the strongest $25 \%$ of cyclones in each season) between 1980-99 and 2081-2100 over North America varies from 12.7\% to $-27.3 \%$ for the spring and from $1.9 \%$ to $-31.5 \%$ for the winter in the 23 models of the Coupled Model Intercomparison Project, phase 5 (CMIP5), although most of these models have a frequency decrease. Colle et al. (2013) found an increase in cyclone intensity along the east coast of North America in the mean of seven CMIP5 GCMs in 2069-98 but no significant changes in the mean of the other eight GCMs.

The coarse-resolution (100-300-km spacing) GCMs typically underestimate the intensity of extratropical cyclones in the North Atlantic Ocean storm track (Chang et al. 2013; Colle et al. 2013; Zappa et al. 2013; Seiler and Zwiers 2016; Seiler et al. 2018). Some studies have found that the extratropical cyclone intensity increases with increasing horizontal resolution (Jung et al. 2006; Champion et al. 2011). Booth et al. (2018) evaluated two CMIP5 GCMs and a downscaled mesoscale model and found that the high-resolution (20-km grid spacing) model generates stronger cyclones than the GCMs based on surface wind speed and precipitation rate. Willison et al. $(2013,2015)$ showed that the response of extratropical cyclones to global warming is amplified in model projection at $20-\mathrm{km}$ grid spacing relative to $120-\mathrm{km}$ grid spacing because the increase in cyclone intensity through latent heat release is enhanced at the finer resolution.

Marciano et al. (2015) simulated 10 relatively strong $(<995 \mathrm{hPa})$ extratropical cyclones over the U.S. East Coast for the current and future climate using a pseudoglobal warming (PGW) approach at 12- and 4-km grid spacing in the Weather Research and Forecasting (WRF; Skamarock et al. 2008) Model. In their PGW approach, the ensemble mean monthly temperature changes from five CMIP3 GCMs were added to the reanalysis data, which were in turn used as initial and boundary conditions for the WRF future runs. They found an increase in cyclone intensity from the enhanced latent heat release within the comma head of the cyclone. Michaelis et al. (2017) used the same PGW approach, using the mean temperature changes from the CMIP5 models for the WRF simulations of 10 winters in the current and future climate. They found a reduction in the total number of strong storms in North Atlantic storm track, but they also found the enhanced cyclone activity with heavier precipitation and stronger lowlevel wind immediately to the east of the U.S. East Coast.

Seiler et al. (2018) used a high-resolution regional model [Canadian Regional Climate Model, version 4 (CanRCM4)] to dynamically downscale a coarse-resolution CMIP5 model (CanESM2), and they found a decrease in rapidly developing extratropical cyclones in both CanESM2 and CanRCM4 along the east coast of North America. In their approach, the horizontal wind fields from the model top to $850 \mathrm{hPa}$ and the temperature in the top three vertical levels are spectrally nudged. As a result, some important fields related to cyclone development, such as the Eady growth rate, in the high-resolution regional model are constrained somewhat by the coarse-resolution CanESM2.

\section{b. Motivation}

Coarse-resolution GCMs have limitations in simulating the extratropical cyclones along the North Atlantic storm track, especially for the intense cyclones. Meanwhile, the GCMs have large uncertainties in the future projections of cyclone activities along the east coast of North America. Dynamical downscaling may reduce the cyclone biases in GCMs, but there are still uncertainties in the future projections (Marciano et al. 2015; Michaelis et al. 2017; Seiler et al. 2018). These uncertainties come from GCM resolution and physics and the different dynamical downscaling approaches. In those recent studies, the input forcing data to the regional model is from one GCM or the mean change of several GCMs. The intermodel variability in GCMs and the impact of dynamical downscaling on that variability have not been systematically investigated. In this study, we downscale two different GCMs to explore the impact this downscaling has on the historical simulations and future cyclone projections, as well as any variability introduced by using two different GCMs.

We apply a dynamical downscaling approach to two CMIP5 GCMs, CCSM4 and GFDL-ESM2M (GFDL hereinafter), for both the historical and future scenarios, respectively, of the representative concentration pathway 8.5 scenario (RCP8.5) experiments, respectively. These two GCMs are selected because they have different historical bias and future projections in cyclones over the U.S. East Coast. GFDL, which has relatively large bias in cyclone frequency and intensity (Colle et al. 2013), is selected to investigate whether the dynamical downscaling can improve cyclone simulation in a GCM that has relatively large bias. The comparison between the two GCMs with different future projections can improve the understanding of the key factors controlling future cyclone changes, as well as the impacts of dynamical downscaling on those changes. Two sets of different grid spacings $\left(1^{\circ}\right.$ and $\left.0.2^{\circ}\right)$ are employed in our WRF runs to investigate the impacts of model resolution. These two models are not enough downscaled GCMs to determine future changes with a fair degree of confidence, so the main focus of this paper is to explore some of the reasons for the differences between the two different model scenarios and resolutions. This study will address the following three questions: 
1) How does dynamical downscaling of two different GCMs affect the frequency and intensity of winter extratropical cyclones for both a historical and latertwenty-first-century period over the east coast of North America and the western Atlantic Ocean?

2) What is the impact of model resolution on the downscaled historical and future simulations of extratropical cyclones?

3) What physical processes are largely responsible for any future change in extratropical cyclones and any differences between the models?

\section{Data and methods}

\section{a. Data}

CMIP5 historical and RCP8.5 runs from CCSM4 $\left(0.94^{\circ} \times 1.25^{\circ}\right)$ and GFDL $\left(2.0^{\circ} \times 2.5^{\circ}\right)$ are selected for dynamical downscaling. Some of the details of these two models are described in Gent et al. (2011) and Donner et al. (2011), respectively. The details of the CMIP5 historical and RCP8.5 experiment design are described in Taylor et al. (2012). The GCM output data used to create the initial and boundary conditions for WRF include 6-h surface pressure and sea level pressure (SLP), 6-h air temperature, wind, and relative humidity on the GCM model levels (26 levels for CCSM4 and 24 levels for GFDL); daily surface snow amount; monthly mean soil temperature and soil moisture; and daily sea surface temperature (SST) from the CCSM4 and GFDL ocean models. Although increasing SST resolution may reduce the storm-track biases (Woollings et al. 2010), we use the relatively low resolution SST from CCSM4 or GFDL to keep consistency between the atmosphere and the SST and to simply focus on the impact of regional model resolution on the downscaling.

As in Colle et al. (2013), the 6-h Climate Forecast System Reanalysis (CFSR; Saha et al. 2010) at $~ 38-\mathrm{km}$ grid spacing is used to verify and compare the cyclone properties with the models. The SLP is used to track cyclones as described below and determine the cyclone intensity. The temperature and wind (horizontal, i.e., $U$ and $V$, components) are used to calculate the important fields related to the extratropical cyclone development, such as surface temperature gradient, upper-level jet, and Eady growth rate.

\section{b. WRF dynamical downscaling}

WRF, version 3.6.1, using the Advanced Research dynamical core (ARW) is employed to dynamically downscale CCSM4 and GFDL. First, we extract the 6-h data for the region of eastern North America and the western Atlantic and for the winter period (from 29 December to 2 April) from the CCSM4 and GFDL

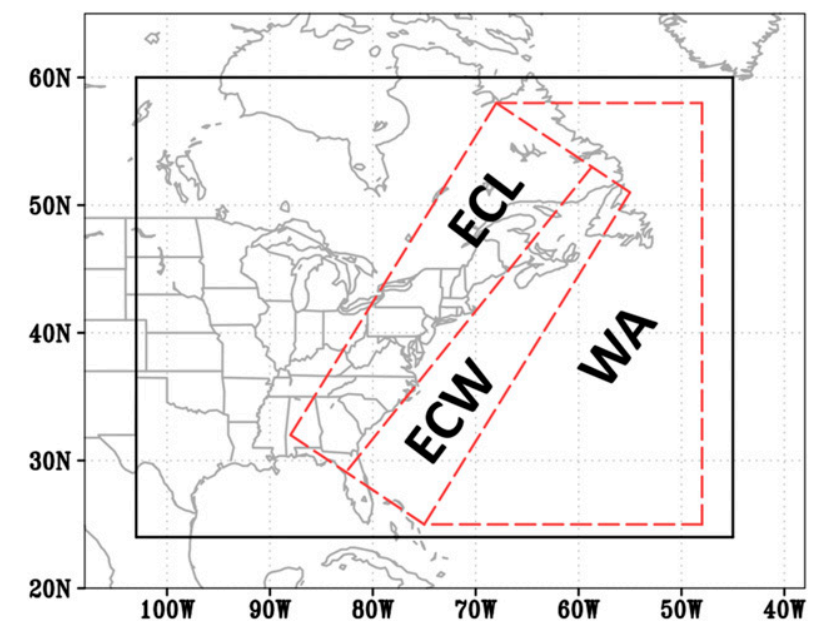

FIG. 1. The domains used in this study. The solid black box is the domain for WRF downscaling; the red dashed boxes are the subregions for cyclone analysis: East Coast Land, East Coast Water, Western Atlantic, and ECWA (ECL + ECW + WA).

historical and RCP8.5 output. Then all of the data are interpolated to a common $1^{\circ} \times 1^{\circ}$ grid using a bilinear interpolation. Last, the data are converted to a WRF Preprocessing System (WPS) intermediate file format. These data preprocessing steps are utilized instead of "ungrib" in WPS so that WPS can read and use the preprocessed GCM data to prepare the input data for WRF.

The WRF domain is from $24^{\circ}$ to $60^{\circ} \mathrm{N}$ and from $103^{\circ}$ to $45^{\circ} \mathrm{W}$ (black box in Fig. 1), which covers the large part of the storm track over the east coast of North America. The historical period is from 1986 to 2005 , which is the last 20 years of the CMIP5 historical experiment, and the future period is from 2080 to 2099 , which is the last 20 years of the CMIP5 twenty-first-century RCP8.5 experiment. Following Willison et al. (2013, 2015), winter is defined as January-March. For each winter WRF is initialized at 29 December and run continuously through the following 2 April. Only the WRF output for January, February, and March is used for the analysis. The physical parameterizations used in WRF include Morrison microphysics (Morrison et al. 2009), Betts-Miller cumulus parameterization (Janjić 1994), RRTM longwave radiation (Mlawer et al. 1997), Goddard shortwave radiation (Chou and Suarez 1999; Chou et al. 2001), Mellor-Yamada-Janjić boundary layer physics (Janjić 1994), and Noah land surface physics (Tewari et al. 2004). These physics schemes were selected on the basis of a set of WRF test runs using the same initial and boundary conditions but eight different sets of physics schemes. The physics schemes from the best member, which had the smallest bias in cyclone frequency and intensity with respect to CFSR, were selected for the WRF runs in this study. Since our future simulations are 
forced by the data from the CMIP5 RCP8.5 experiment, the $\mathrm{CO}_{2}$ concentration in the longwave radiation scheme (RRTM) for future runs is modified to 936 ppmv, which is the value at the end of twenty-first century in the CMIP5 RCP8.5 scenario (Meinshausen et al. 2011). There are two sets of WRF runs with the same physics and setup: a high-resolution run at $0.2^{\circ}$ grid spacing (WRF-HR) and a coarser run at $1.0^{\circ}$ (WRF-LR).

\section{c. Cyclone tracking and cyclone-relative approach}

The "TRACK" scheme developed by Hodges (1994, 1995) is employed to track cyclones using SLP following Colle et al. (2013). The SLP planetary scales with total wavenumber less than or equal to 5 are removed since the SLP is strongly influenced by the large spatial scales and the strong background flows; the SLP is also truncated at the small scales with total wavenumber larger than 70 to remove the small-scale noise. The TRACK scheme can identify the minima in a time series of the SLP field as the potential cyclone centers and link these centers to obtain the cyclone tracks based on a cost function. Last, the low SLP centers that exist for too short of a time or are too stationary are removed; only the cyclones existing for at least $24 \mathrm{~h}$ and moving at least $1000 \mathrm{~km}$ over their lifetime are retained for further analysis. Although there are some uncertainties using different cyclone-tracking methods, consistency across the methods is generally larger for relatively deep cyclones (Neu et al. 2013). Chang (2014) showed that the background SLP removal could impact the CMIP5 projected Pacific winter cyclone activity as a result of a projected deepening of the climatological mean Aleutian low. However, the future change of climatological mean SLP over the western North Atlantic (the region in our study) is weaker than that for the North Pacific region (Chang 2014), indicating a smaller uncertainty over this region from the SLP background. Following Colle et al. (2013), the cyclone centers are categorized into three subregions as shown in Fig. 1: the east coast over land (ECL), the east coast over water (ECW), and the western Atlantic (WA).

A cyclone-relative approach (Zhang and Colle 2017) is utilized to extract and composite the important related fields around each cyclone center. The difference in this study as compared to Zhang and Colle (2017) is that 6-hourly data are utilized rather than daily data for the cyclone-relative analysis. According to the time and position of the cyclone center, a cyclone-relative box $(2400 \mathrm{~km} \times 2400 \mathrm{~km})$ around each cyclone center is defined and the related fields within this box are extracted and recorded for the corresponding cyclone center. This size of cyclone-relative box is large enough to spatially cover all or most of an extratropical cyclone. The cyclone-relative fields (e.g., precipitation) can also be placed back onto the geographic map according to their cyclone center position to create the geospatialrelative fields associated with a particular subset of cyclones. The geospatial-relative fields associated with cyclones can be somewhat sensitive to the size of the cyclone-relative box. The sensitivity of the precipitation rate associated with cyclones to the size of the box was tested using a smaller $(1800 \mathrm{~km} \times 1800 \mathrm{~km})$ box. The difference in historical cyclone relative precipitation rate between the results from the two different box sizes was $7 \%-16 \%$ over our ECL + ECW + WA (ECWA) domain in all experiments, and it did not have a large impact on the conclusion about the future changes.

\section{Historical evaluation}

\section{a. The differences of cyclone activities in historical simulations}

Figure 2 shows the cyclone track density (cyclones per winter per $50000 \mathrm{~km}^{2}$ ) for CFSR and the individual model runs during the historical winters (1986-2005). Although the GCM and WRF runs reproduce the cyclone track density maximum along the east coast of North America, all models underestimate the cyclone track density maximum by $15 \%-30 \%$ over this region. CFSR has 44.5 cyclone tracks per winter within the ECWA region, while GFDL and CCSM4 have 33.2 (26\% underprediction relative to CFSR) and 38.3 (14\% underprediction) cyclones, respectively. WRF-HR (39.2 cyclones) and WRF-LR (36.4 cyclones) forced by GFDL (G-WRF-HR and G-WRF-LR) reduce the underprediction from $26 \%$ in GFDL to $12 \%$ and $18 \%$, respectively. WRF-HR (37.4 cyclones and $16 \%$ underprediction) and WRF-LR (35.8 cyclones and 19\% underprediction) forced by CCSM4 (C-WRF-HR and C-WRF-LR) have slightly larger underprediction than CCSM4. Meanwhile, the regions with relatively large cyclone track density $\left(>1.8\right.$ cyclones per winter per $\left.50000 \mathrm{~km}^{2}\right)$ in C-WRF (forced by relatively higher-resolution CCSM4 SST) are located more offshore (by $2^{\circ}-4^{\circ}$ ) over the coast of the northeastern United States than in G-WRF (forced by relatively lower resolution GFDL SST). This is consistent with the result from Woollings et al. (2010), who found that increasing SST resolution shifts the storm track slightly off the coast.

The lowest central SLP along each cyclone track is defined as the cyclone intensity. Figure 3 shows the intensity distribution of the cyclones within the large ECWA region. The number of relatively weak cyclones $(>1010 \mathrm{hPa}$ ) in both of the GCMs is close to CFSR, but 


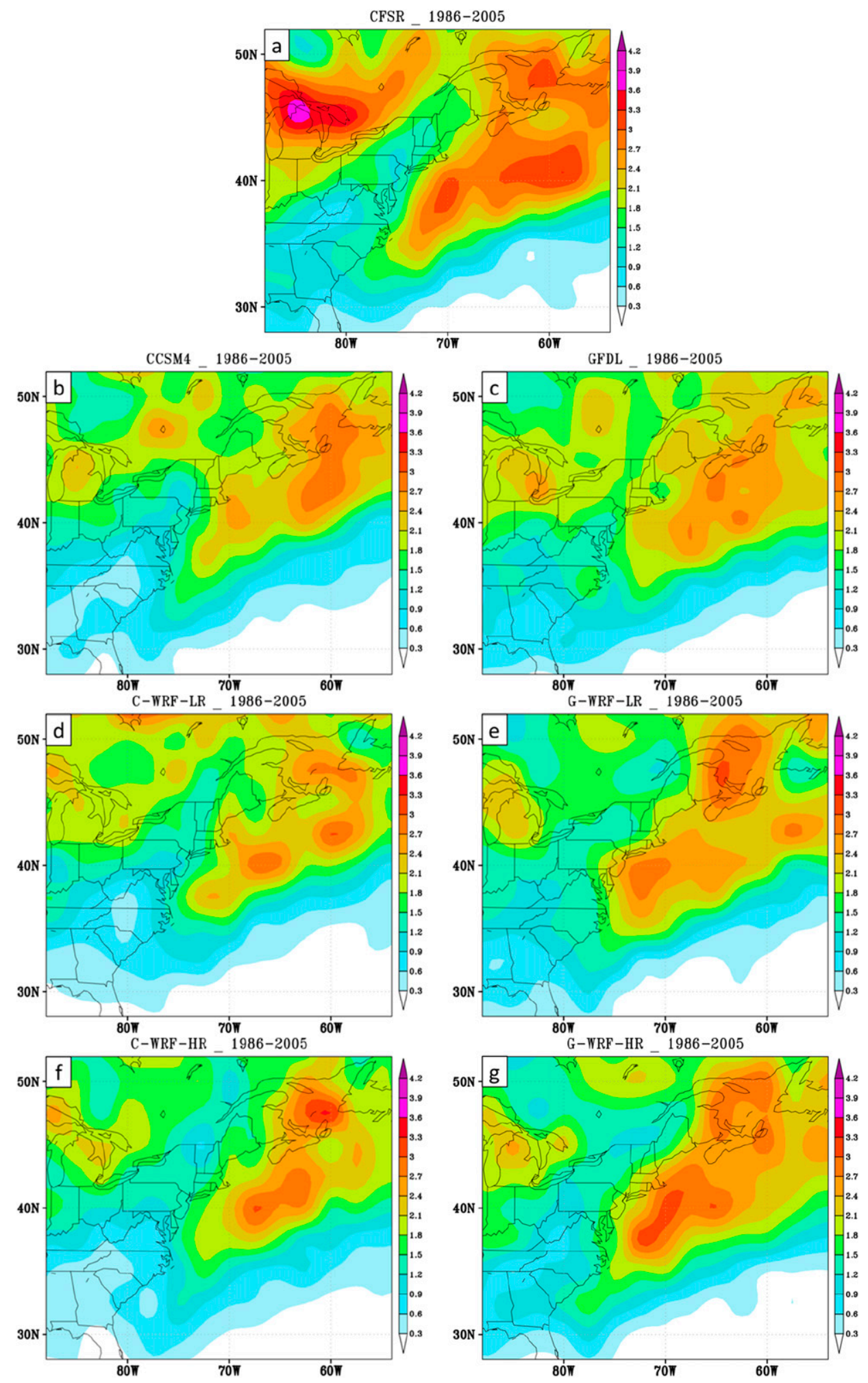

FIG. 2. The cyclone track density (cyclones per winter per $50000 \mathrm{~km}^{2}$ ) for the historical winters (1986-2005) for (a) CFSR, (b) CCSM4, (c) GFDL, (d) C-WRF-LR, (e) G-WRF-LR, (f) C-WRF-HR, and (g) G-WRF-HR. 

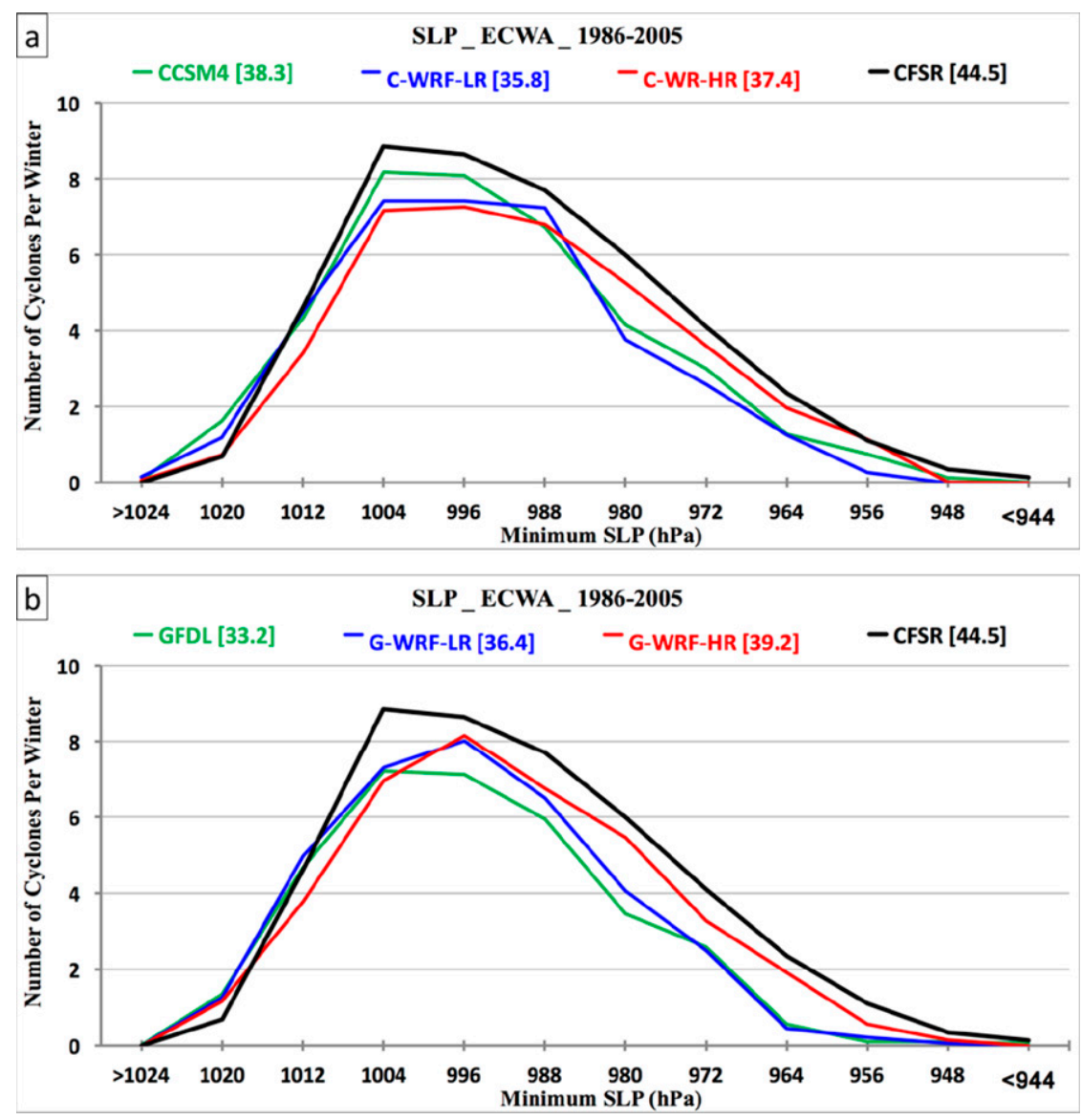

FIG. 3. The distribution of cyclone minimum central SLP along cyclone tracks within the ECWA region in historical winters for (a) CFSR (black), CCSM4 (green), C-WRF-LR (blue), and C-WRF-HR (red) and (b) CFSR [black, repeated from (a)], GFDL (green), G-WRF-LR (blue), and G-WRF-HR (red). The number next to the model label is the total number of cyclone tracks (per winter) within the ECWA region.

the GCMs underestimate the number of cyclones that are deeper than $1010 \mathrm{hPa}$ by $17 \%-30 \%$, especially in GFDL. The intensity distribution in WRF-HR is shifted toward more intense storms as compared with the GCMs, and it is closer to the CFSR results. Meanwhile, the intensity distribution in WRF-LR is closer to the distribution in the corresponding GCM.

Figure 4 shows the density of the more rapidly deepening cyclones [by more than $-5 \mathrm{hPa}(6 \mathrm{~h})^{-1}$ ]. Overall, the GCMs and the WRF-LR runs have too few $(60 \%-$ $70 \%$ of CFSR) rapidly deepening events relative to CFSR. The WRF-HR runs have more rapid deepening cases ( $80 \%-90 \%$ of CFSR) and reduce the negative bias in the GCMs and WRF-LR. The location for the rapid deepening density maximum in the WRF runs is similar to the corresponding GCM used for boundary conditions, shifting to the northeast of the CFSR maximum in WRF forced by CCSM4 and to the southwest in WRF forced by GFDL (Fig. 4). Both of the WRF-HR runs forced by CCSM4 and GFDL have $10 \%-35 \%$ more rapidly deepening rates than the GCMs and WRF-LR runs (Fig. 5).

\section{b. The physical processes related to the different cyclone activities}

To explore the physical processes responsible for the different cyclone properties in the different models, we examined the low-level baroclinicity, the upper-level jet $(250 \mathrm{hPa})$, and the latent heat release on both the cyclone-relative grid and the geographical map. For the cyclone-relative composite, we focus on cyclone centers within the ECL and ECW regions. The results for the WA cyclone centers are similar in the historical period and thus are not shown.

All of the composite cyclones for the different models have a relatively strong surface temperature gradient region extending to the northeast of the cyclogenesis point (Fig. 6). However, the surface temperature 


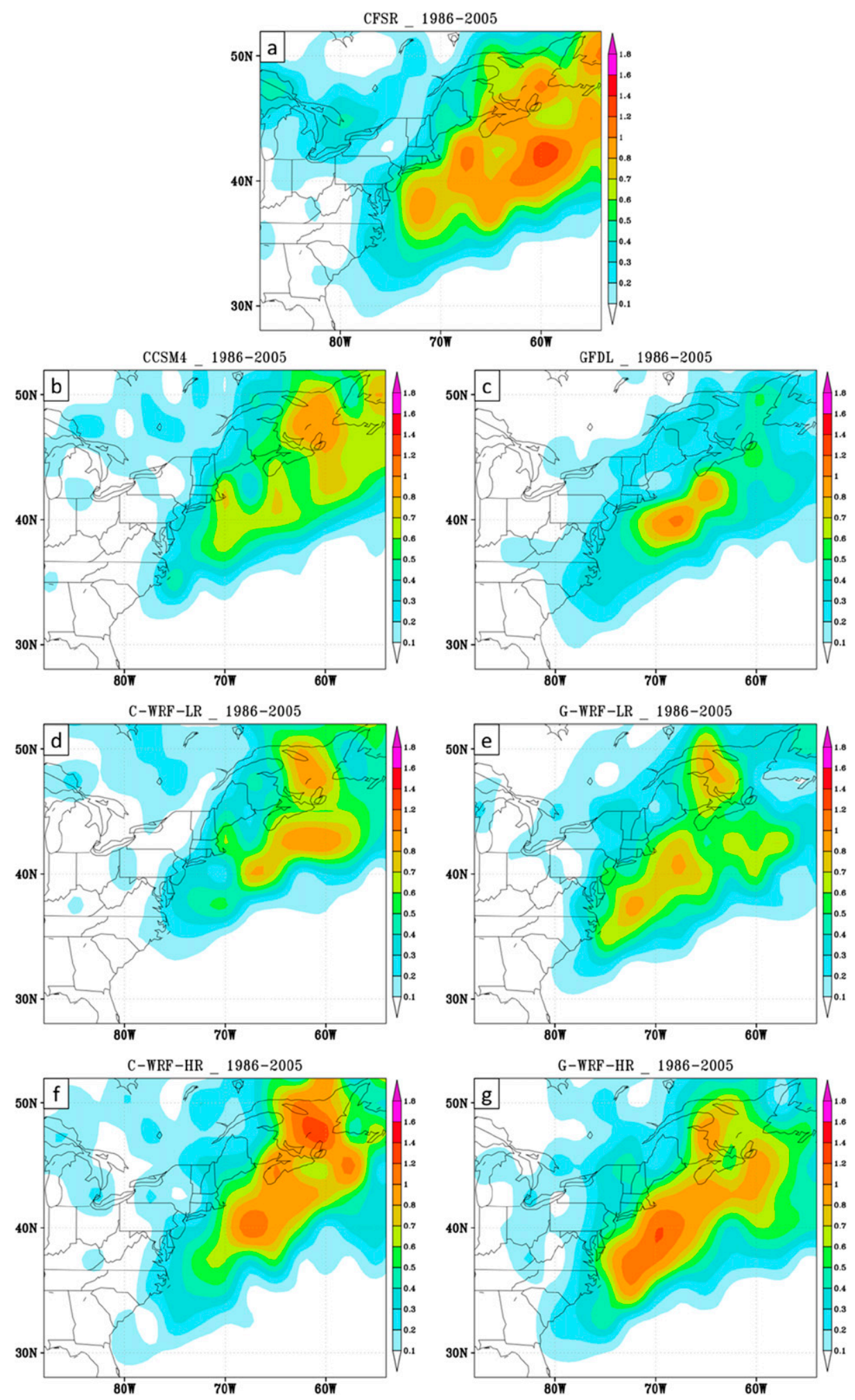

FIG. 4. The density of rapid deepening cyclones [by more than $-5 \mathrm{hPa}(6 \mathrm{~h})^{-1}$ ] showing the number of cases per winter per $50000 \mathrm{~km}^{2}$ during the historical winters for (a) CFSR, (b) CCSM4, (c) GFDL, (d) C-WRF-LR, (e) G-WRF-LR, (f) C-WRF-HR, and (g) G-WRF-HR. 

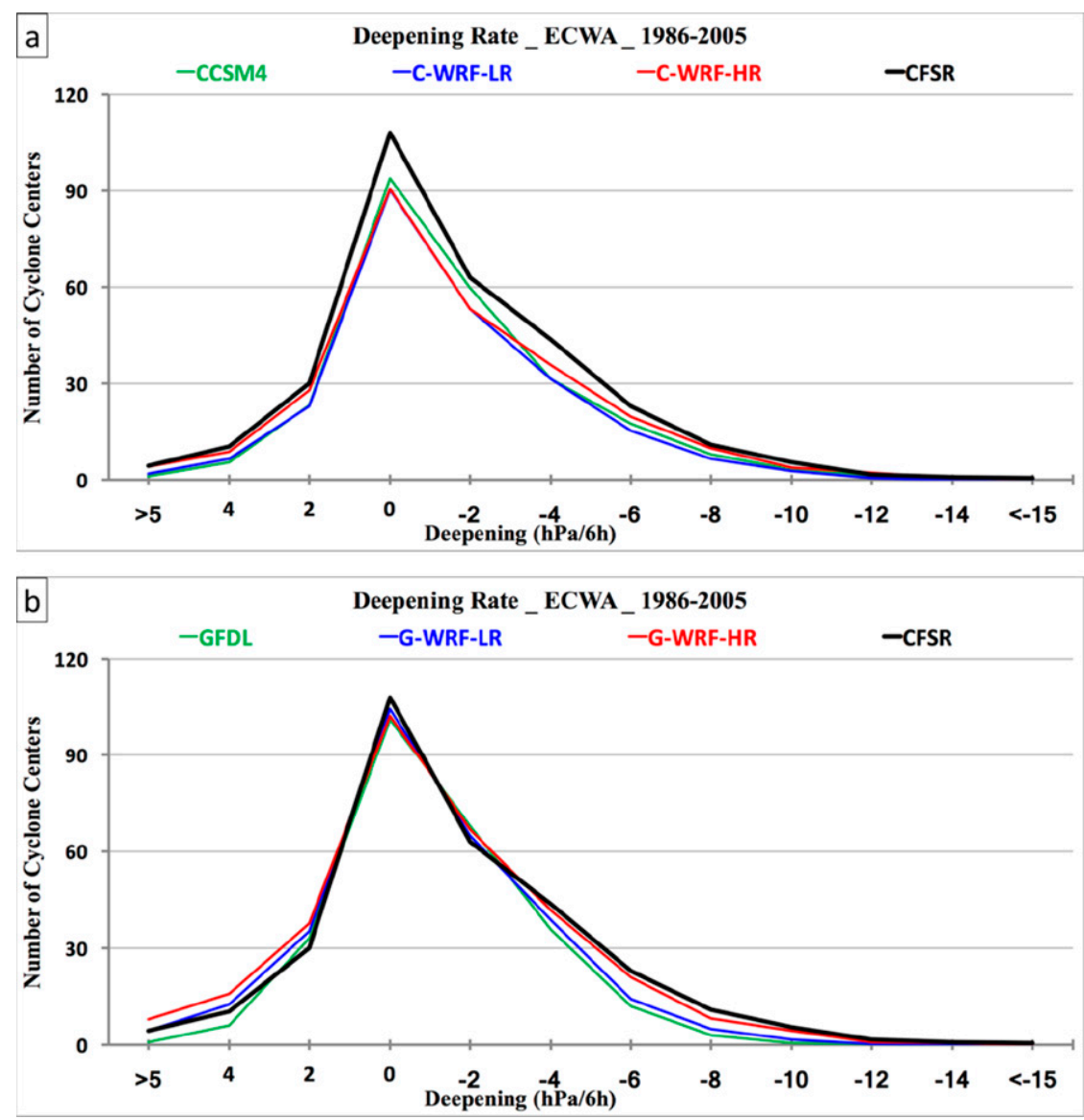

FIG. 5. As in Fig. 3, but for cyclone deepening rates $\left[\mathrm{hPa}(6 \mathrm{~h})^{-1}\right.$, with negative values deepening].

gradient in GFDL is only $50 \%-80 \%$ of the CFSR temperature gradient, while the CCSM4 temperature gradient is $80 \%-90 \%$ of CFSR. Thus, the lack of surface baroclinicity is likely one important reason for the large negative bias in cyclone frequency and rapid deepening in GFDL, and GCM resolution could be one factor affecting the surface temperature gradient. The surface temperature gradient in the WRF runs forced by GFDL is much stronger $(90 \%-110 \%$ of CFSR) than in GFDL, whereas the WRF run forced by CCSM4 has a slightly stronger temperature gradient than CCSM4. Overall, both of the WRF-HR and WRF-LR runs generate a stronger surface temperature gradient that is closer to CFSR than the GCMs. Even though C-WRF-LR $\left(1.0^{\circ} \times\right.$ $\left.1.0^{\circ}\right)$ has a resolution that is comparable to that of CCSM4 $\left(0.94^{\circ} \times 1.25^{\circ}\right)$, it has a stronger surface temperature gradient than CCSM4. This indicates that model physics plays an important role in some of the differences. On the other hand, given the same model physics and input data (including SST), the difference of surface temperature gradient between WRF-HR and WRF-LR is very small
$(5 \%-10 \%)$. Thus, the resolution of WRF does not have a large impact on the surface temperature gradient when the physics and SST are the same.

The climatological mean 850-500 -hPa Eady growth rate [calculated following Colle et al. (2013)] in the 20 historical winters has a maximum of $1.06 \mathrm{day}^{-1}$ over the offshore region of the northeastern United States and a domain $\left(80^{\circ}-50^{\circ} \mathrm{W}\right.$ and $36^{\circ}-52^{\circ} \mathrm{N}$, which covers the high Eady growth region) average of $0.92 \mathrm{day}^{-1}$ in CFSR (Fig. 7). In CCSM4 (GFDL) the domain-averaged Eady growth rate is $95 \%(92 \%)$ of CFSR. The maximum of Eady growth rate is shifted $3^{\circ}-5^{\circ}$ to the northeast in CCSM4 and $\sim 10^{\circ}$ to the east in GFDL relative to CFSR. GFDL has the weakest Eady growth rate, which is consistent with its weaker surface baroclinicity. In C-WRF-HR (G-WRF-HR), the domain-averaged Eady growth rate is close $[99 \%(99 \%)]$ to CFSR, but the maximum location is shifted to the northeast or east similar to its parent GCM. The domain-averaged Eady growth rate in C-WRF-LR (G-WRF-LR) is close to the intensity in the GCMs, about $96 \%$ (95\%) of CFSR. 

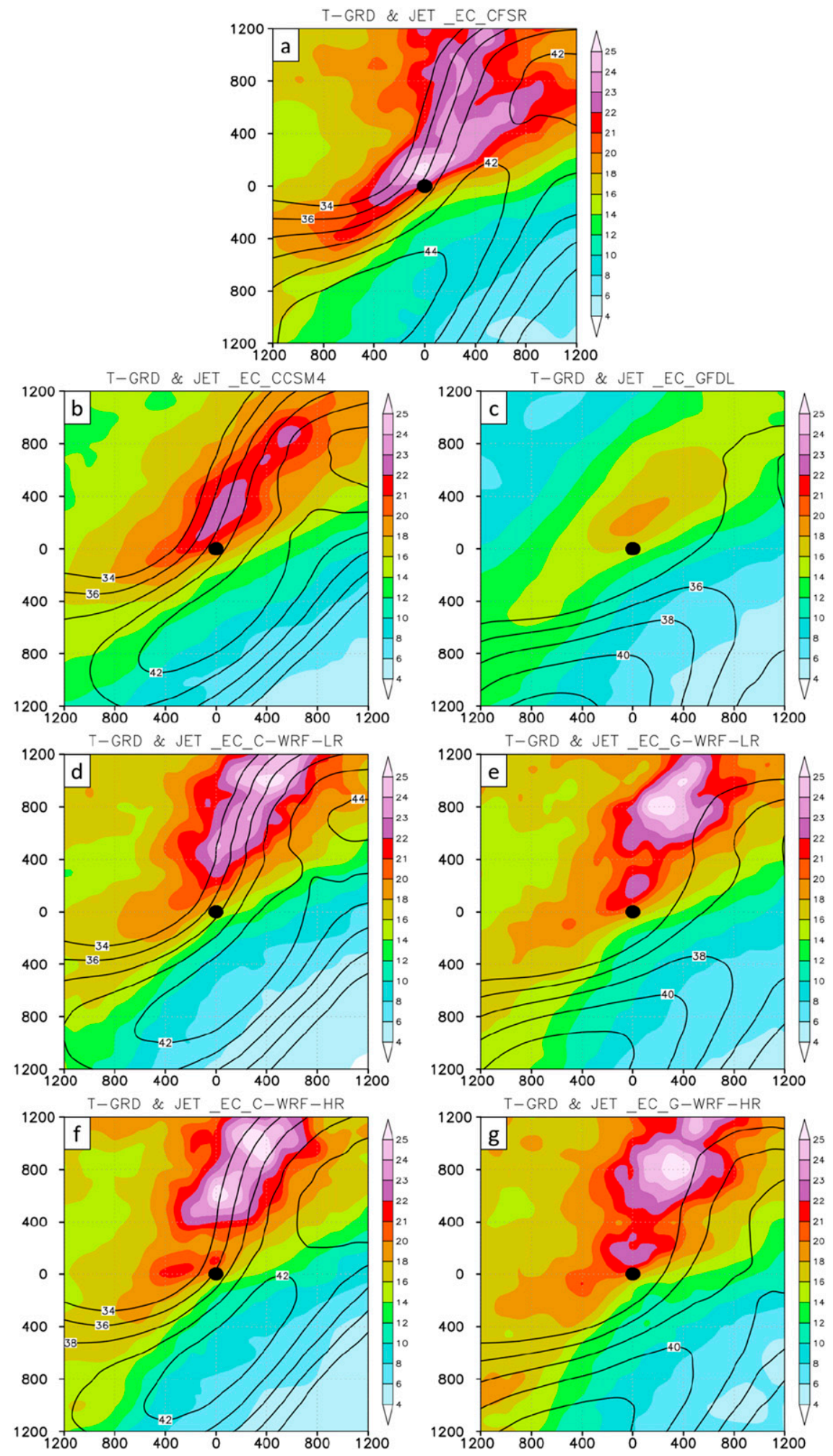

FIG. 6. The composite surface temperature gradient [color fill; $\left.\mathrm{K}(1000 \mathrm{~km})^{-1}\right]$ at the time of cyclogenesis (start of cyclone track) and 250-hPa wind speed (contours every $2 \mathrm{~m} \mathrm{~s}^{-1}$ ) for all cyclone centers within the ECL + ECW region for (a) CFSR, (b) CCSM4, (c) GFDL, (d) C-WRF-LR, (e) G-WRF-LR, (f) C-WRF-HR, and (g) G-WRF-HR. The black dot is the position of the cyclone center. 

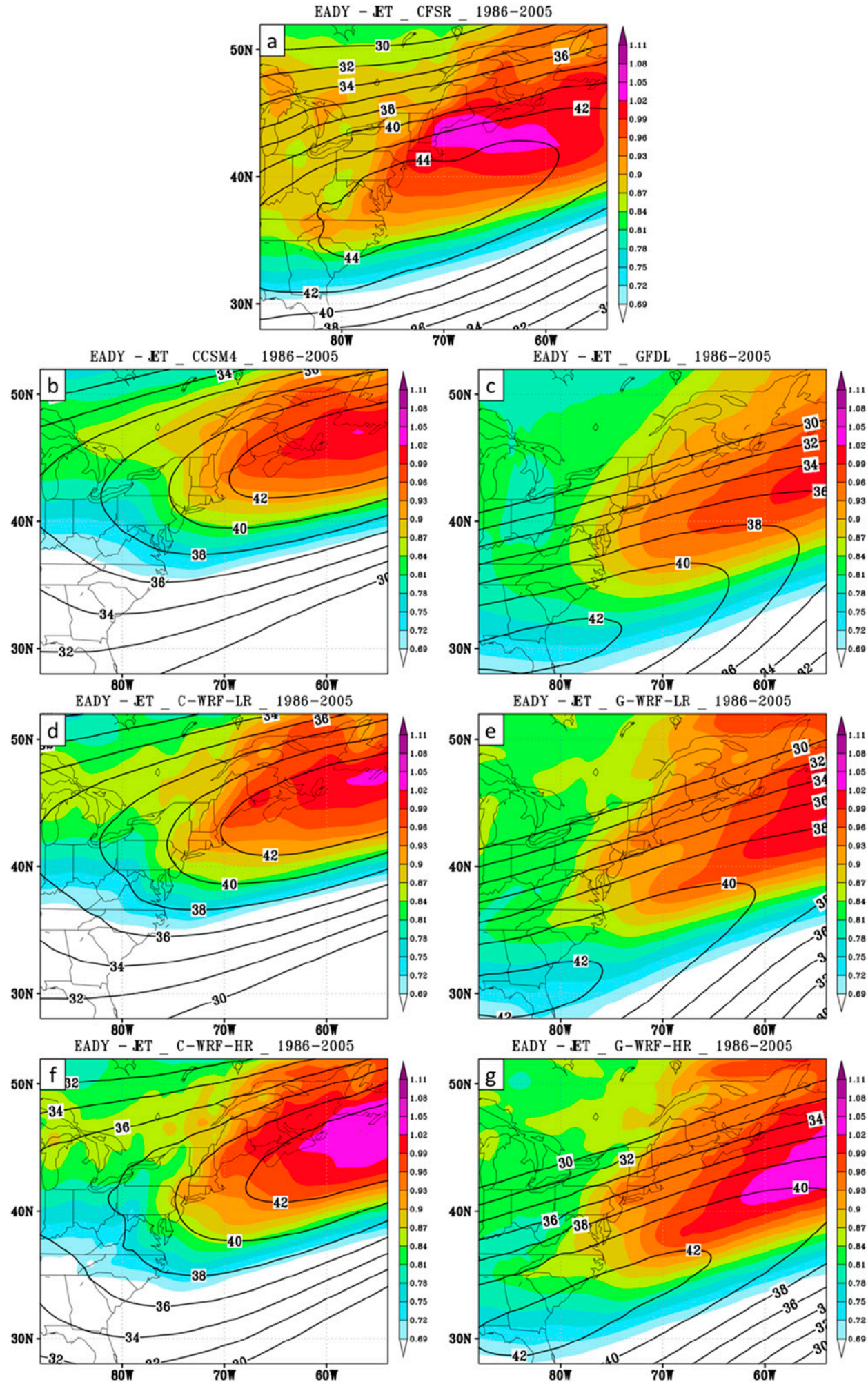

FIG. 7. The 250-hPa wind speed (contoured every $2 \mathrm{~m} \mathrm{~s}^{-1}$ ) and the 850-500-hPa Eady growth rate (color fill; day ${ }^{-1}$ ) for the historical winters for (a) CFSR, (b) CCSM4, (c) GFDL, (d) C-WRF-LR, (e) G-WRF-LR, (f) C-WRF-HR, and (g) G-WRF-HR. 

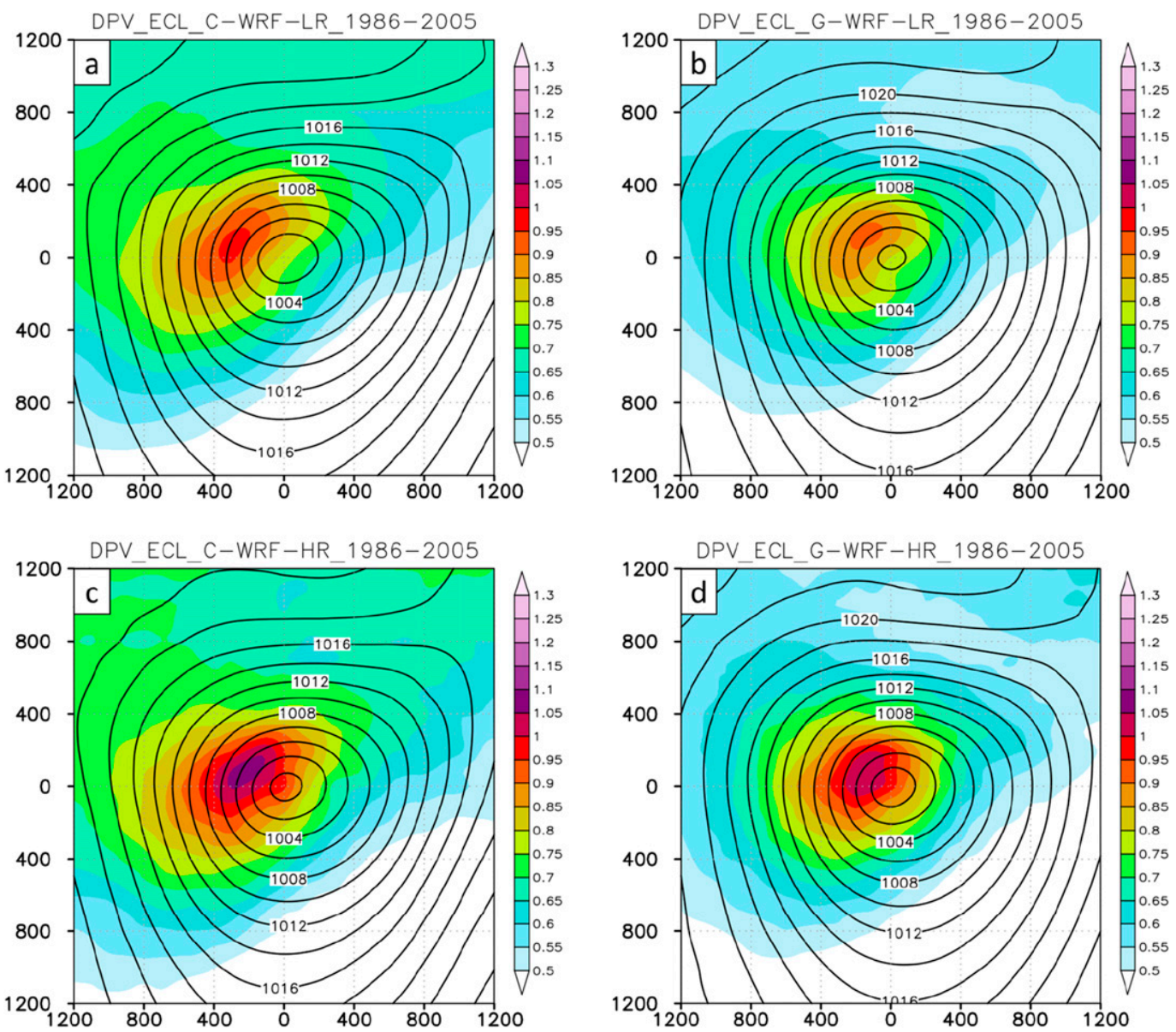

FIG. 8. The cyclone composite SLP (contoured every $2 \mathrm{hPa}$ ) and 900-750-hPa DPV [color fill; PVU (1 PVU = $10^{-6} \mathrm{~K} \mathrm{~kg}^{-1} \mathrm{~m}^{2} \mathrm{~s}^{-1}$ )] for the cyclones within the ECL region in historical winters for (a) C-WRF-LR, (b) G-WRF-LR, (c) C-WRF-HR, and (d) G-WRF-HR.

The position of the upper-level jet in the WRF runs is controlled by the corresponding GCM large-scale flow, shifting about $1000 \mathrm{~km}$ to the northeast in the CCSM4 group and about $1200 \mathrm{~km}$ to the southwest in the GFDL group relative to the jet position in CFSR (Fig. 7). This is consistent with the maximum in cyclone rapid deepening located to the north in WRF forced by CCSM4 and to the southwest in WRF forced by GFDL (Fig. 4). The cyclone center is located at the left side of the jet exit in CFSR (Fig. 6), which is often a favorable region for upward motion and cyclone deepening; however, the models have biases in the position of the jet related to the cyclone center. The CCSM4 group has the cyclone center too close to the jet core, while the cyclone center in the GFDL group is too far north from the jet. This bias in cyclone position relative to the jet also likely contributes to the negative biases of the cyclone rapid deepening and intensity in the models. The bias in upper-level jet intensity is small in all model runs (Figs. 6 and 7). CCSM4 and its WRF runs have a maximum wind speed that is $\sim 2 \mathrm{~m} \mathrm{~s}^{-1}$ weaker than that of CFSR $\left(44 \mathrm{~m} \mathrm{~s}^{-1}\right)$. In G-WRF-HR the upper-level jet is slightly stronger than in G-WRF-LR and GFDL, with a larger area covered by $>40 \mathrm{~m} \mathrm{~s}^{-1}$ over the North Atlantic, but is still somewhat weaker than CFSR.

The impact of latent heat release is quantified using the $900-750-\mathrm{hPa}$ diabatic potential vorticity (DPV) as in Marciano et al. (2015). Similar with the cyclone intensity distribution in Fig. 3, the composite cyclone in WRF-HR is $1.6-1.8 \mathrm{hPa}$ deeper than WRF-LR (Fig. 8). The central SLP of the composite cyclone for the ECL region is $1000.1 \mathrm{hPa}(999.8 \mathrm{hPa})$ in C-WRF-LR (G-WRF-LR) and $998.3 \mathrm{hPa}(998.2 \mathrm{hPa})$ in C-WRF-HR (G-WRFHR). The DPV is $10 \%-15 \%$ stronger in WRF-HR than the DPV in WRF-LR over the comma head of the cyclone, which is consistent with the difference of precipitation rate $(\sim 10 \%$ greater; not shown) between WRF-HR and WRF-LR. Given the relatively small differences in the baroclinicity and upper-level jet between C-WRF-HR (G-WRF-HR) and C-WRF-LR 
(G-WRF-LR), the stronger latent heat release is likely an important factor contributing to the difference in cyclone intensity between WRF-HR and WRF-LR.

\section{Future changes}

\section{a. Differences in future projections}

For the 2080-99 winters the cyclone track density in CCSM 4 increases $10 \%-40 \%$ along the east coast of North America (Fig. 9), and there is a $10 \%-20 \%$ decrease over some regions of the western Atlantic Ocean. The total number of cyclone tracks within the ECWA region is 37.5 per winter in CCSM4, which is very close to the historical number (38.3). C-WRF-LR has a similar pattern change to CCSM4 and has 34.4 cyclones within the ECWA region, which is 1.2 fewer than the historical number. Meanwhile, C-WRF-HR has a slightly stronger increase along the coast and weaker decrease over the ocean and has 38.7 cyclones, which is 1.3 more than the historical number. The increase in cyclone track density along the east coast in the CCSM4 group is statistically significant at the $90 \%$ confidence level by resampling 1000 times using the bootstrap approach (Diaconis and Efron 1983). In contrast, the GFDL and associated G-WRF runs have a significant $(90 \%$ confidence level) decrease $(10 \%-40 \%)$ in track density over the western Atlantic, while there is little change along the East Coast region. The total number of cyclone tracks within the ECWA region is 28.9 for GFDL, 31.0 for G-WRF-LR, and 35.3 for G-WRF-HR, which are $10 \%-16 \%$ fewer than the historical numbers.

For the ECL region the future frequency for CCSM4 cyclones increases for most central pressure categories, while the GFDL frequency decreases for most categories (Fig. 10). The future change in the WRF cyclone numbers is strongly constrained by the corresponding GCM, with the WRF runs forced by CCSM4 and GFDL increasing and decreasing, respectively. Meanwhile, in C-WRF-HR the total number of strong cyclone centers that are deeper than $975 \mathrm{hPa}$ increases from 2.70 per winter in the historical period to 3.25 in the future period, which is a $20 \%$ significant (at $90 \%$ confidence level) increase (Fig. 10). In contrast, the number of strong $(<975 \mathrm{hPa})$ cyclone centers is 1.95 per winter in C-WRF-LR and 2.05 in CCSM4 during the future period, with nearly neutral changes $(<5 \%)$ relative to the historical period. The future change in cyclone deepening rate (Fig. 11) is similar to the intensity changes. In the CCSM4 group there are more cyclone deepening cases [deepening rate of more than $-1 \mathrm{hPa}(6 \mathrm{~h})^{-1}$ ], whereas in the GFDL group there is a decrease for nearly all bins. C-WRF-HR has a $20 \%$ increase in rapid deepening events [by more than $-5 \mathrm{hPa}(6 \mathrm{~h})^{-1}$ ], while that increase is much smaller in C-WRF-LR and CCSM4. Overall, within the ECL region the future change in cyclones in CCSM4 and GFDL are nearly opposite, and the changes in C-WRF-HR imply an increase in the strong cyclones with rapid deepening. Over the WA region, the future changes in the distributions of cyclone intensity and deepening rate exhibit decreases $(5 \%-20 \%)$ for most pressure categories in the CCSM4 group and larger decreases $(10 \%-40 \%)$ in the GFDL group (not shown).

\section{b. Physical processes related to different future changes}

To explore the physical processes related to the different future cyclone changes in the models, we use the same approach as the historical period above. Overall, the future surface temperature increase in the CCSM4 group is $0.5-2.0 \mathrm{~K}$ larger than in the GFDL group over the western Atlantic and eastern North America (Fig. 12). The larger temperature increase in CCSM4 results in a larger $(5 \%-16 \%)$ surface moisture increase than the GFDL group (not shown). The spatial pattern of surface temperature increase is similar in all models, with a larger increase $(3.0-6.0 \mathrm{~K})$ over land and at relatively higher latitudes and a smaller increase $(1.5-3.0 \mathrm{~K})$ over the ocean and lower latitudes. As a result, the surface temperature gradient decreases significantly ( $90 \%$ confidence level) by $5 \%-20 \%$ over most regions of the east coast of North America (ECL + ECW) in all model projections (Fig. 12). However, the $5 \%-10 \%$ decrease of surface temperature gradient in the CCSM4 and C-WRF runs is less than the decrease in the GFDL group (5\%$20 \%$ ). Meanwhile, the decrease for CCSM4 is located farther offshore than where the historical temperature gradient is a maximum (red lines in Fig. 12). In contrast, the decrease of surface temperature gradient in the GFDL group occurs along the coast. The $850-\mathrm{hPa}$ temperature gradient has a similar decrease (not shown), but it is $5 \%-10 \%$ less than the surface. Overall, the low-level baroclinicity decrease is weaker and located more offshore with smaller impact on the cyclone changes over the ECL region in the CCSM4 group, while the baroclinicity decrease is larger and located just along the coast in the GFDL group.

We also composited the 850-500-hPa Eady growth rate around the cyclone center. Overall, the future Eady growth rate decreases in both the ECL and WA regions for the WRF runs forced by CCSM4 and GFDL (Fig. 13). The decrease is weak $(\sim 5 \%)$ and relatively farther away from the cyclone center within the ECL region (Figs. 13a-d), with only C-WRF-LR having a weak decrease close to the cyclone center over the warm sector. However, the decrease for the cyclone in the WA region 

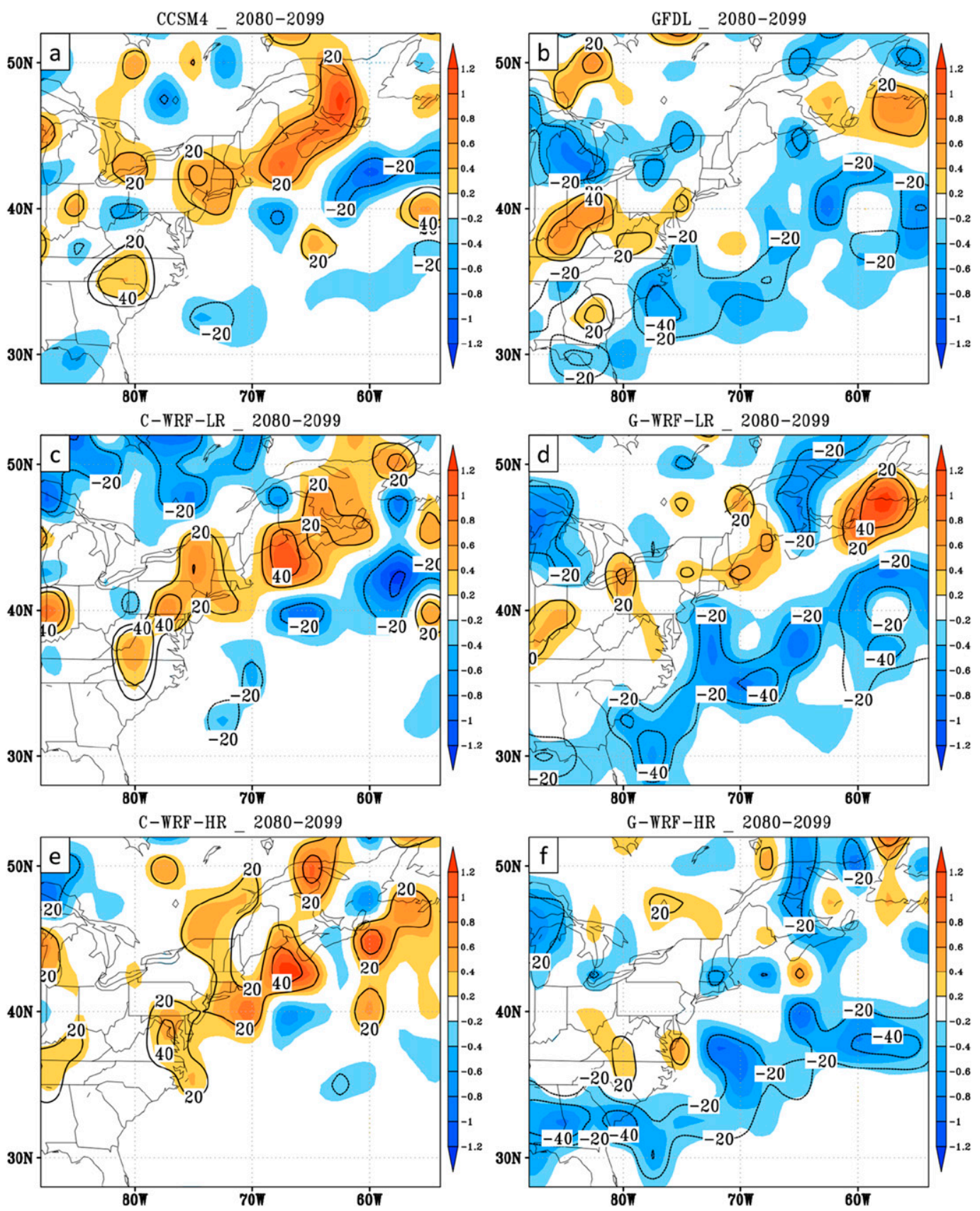

FIG. 9. The change in cyclone track density (color fill; per winter per $50000 \mathrm{~km}^{2}$ ) and the percentage change (contoured every 20\%) for the future (2080-99) relative to the historical (1986-2005) winters for (a) CCSM4, (b) GFDL, (c) C-WRF-LR, (d) G-WRF-LR, (e) C-WRF-HR, and (f) G-WRF-HR.

is larger $(\sim 10 \%)$ and significant ( $95 \%$ confidence level) around the cyclone center, especially in the WRF runs forced by GFDL (Figs. 13e-h). In comparison with the difference in future change between the ECL and the WA regions, the difference between WRF-HR and WRF-LR is relatively small; thus, model resolution has a relatively small impact on the future change of Eady growth rate.
The upper-level jet in the CCSM4 and C-WRF runs is slightly stronger $(\sim 5 \%)$ during the future period (Fig. 14), especially in C-WRF-HR, and this increase in 250-hPa wind speed is situated mainly along the coastal region. The winds in GFDL and G-WRF runs increase over a broad region along the north side of the jet, which implies a poleward shift of the jet. This shift is more obvious in G-WRF-HR, which favors a decrease in 


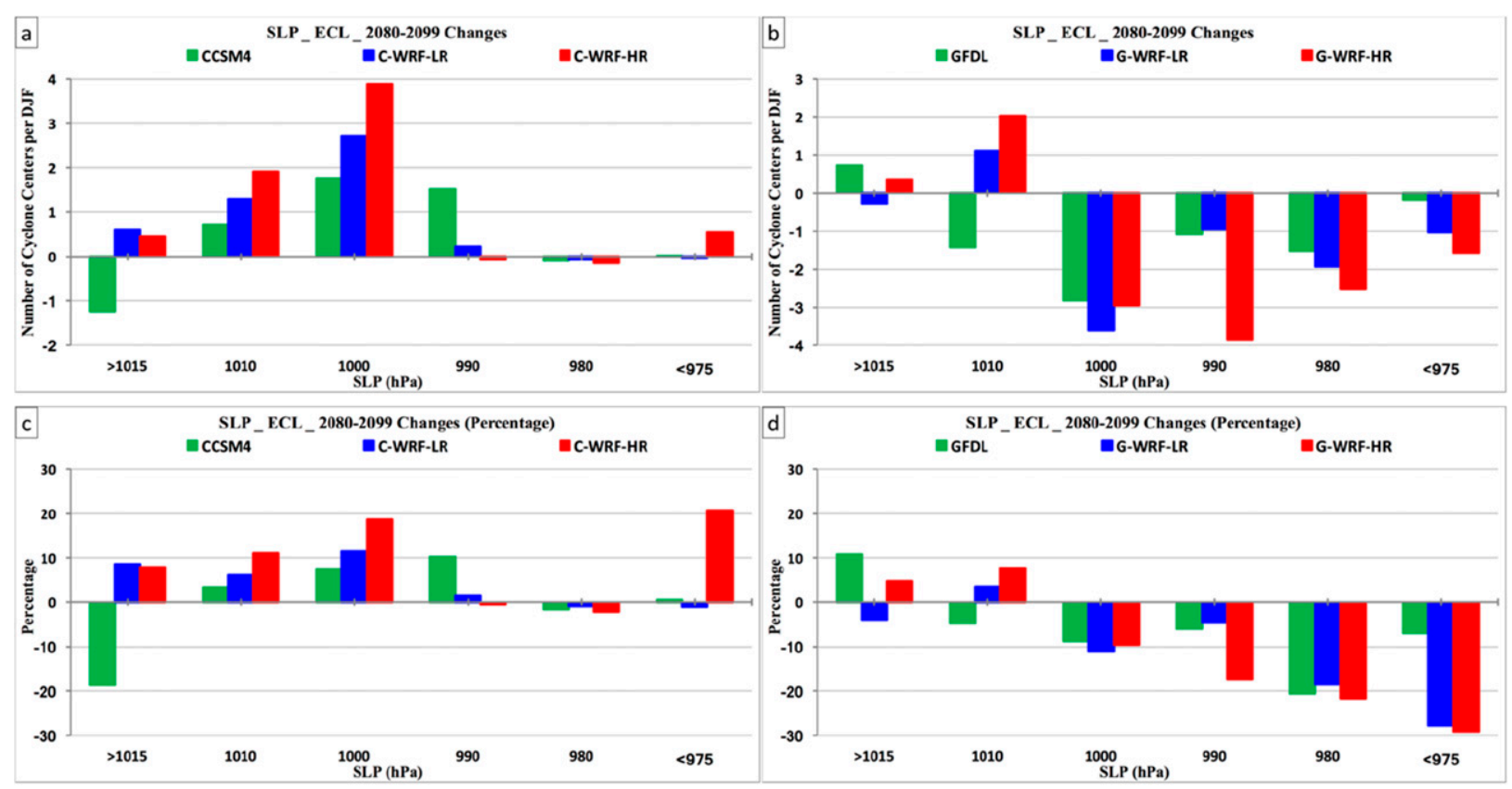

FIG. 10. The future change in the distribution of cyclone intensities for storms within the ECL region for (a) CCSM4 (green), C-WRF-LR (blue), and C-WRF-HR (red) and (b) GFDL (green), G-WRF-LR (blue), and G-WRF-HR (red). (c),(d) As in (a) and (b), but for the percentage changes.

cyclone frequency at the lower latitudes in the GFDL group. The upper-level PV (500-200 hPa) has a weak decrease (about $-5 \%$ ), which is not significant, around the ECL region in the CCSM4 group but is nearly neutral in the GFDL group (not shown).
The future change of cyclone-relative precipitation rate (normalized to each cyclone center) on the geographic map was calculated to focus on the precipitation change associated with cyclones. The precipitation rate increases over most regions in the CCSM4 group, but
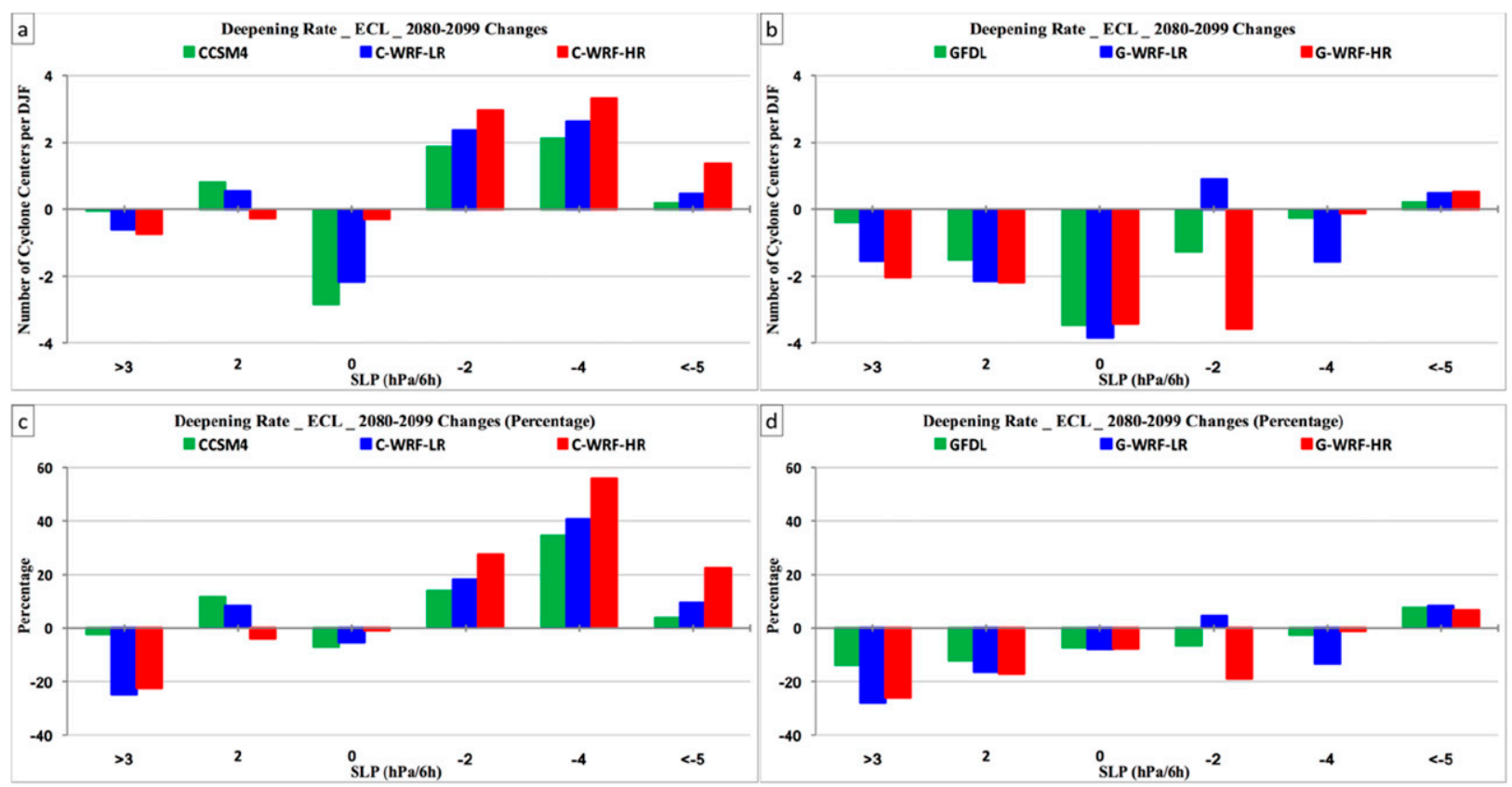

FIG. 11. As in Fig. 10, but for the cyclone deepening rate [hPa $\left.(6 \mathrm{~h})^{-1}\right]$. 

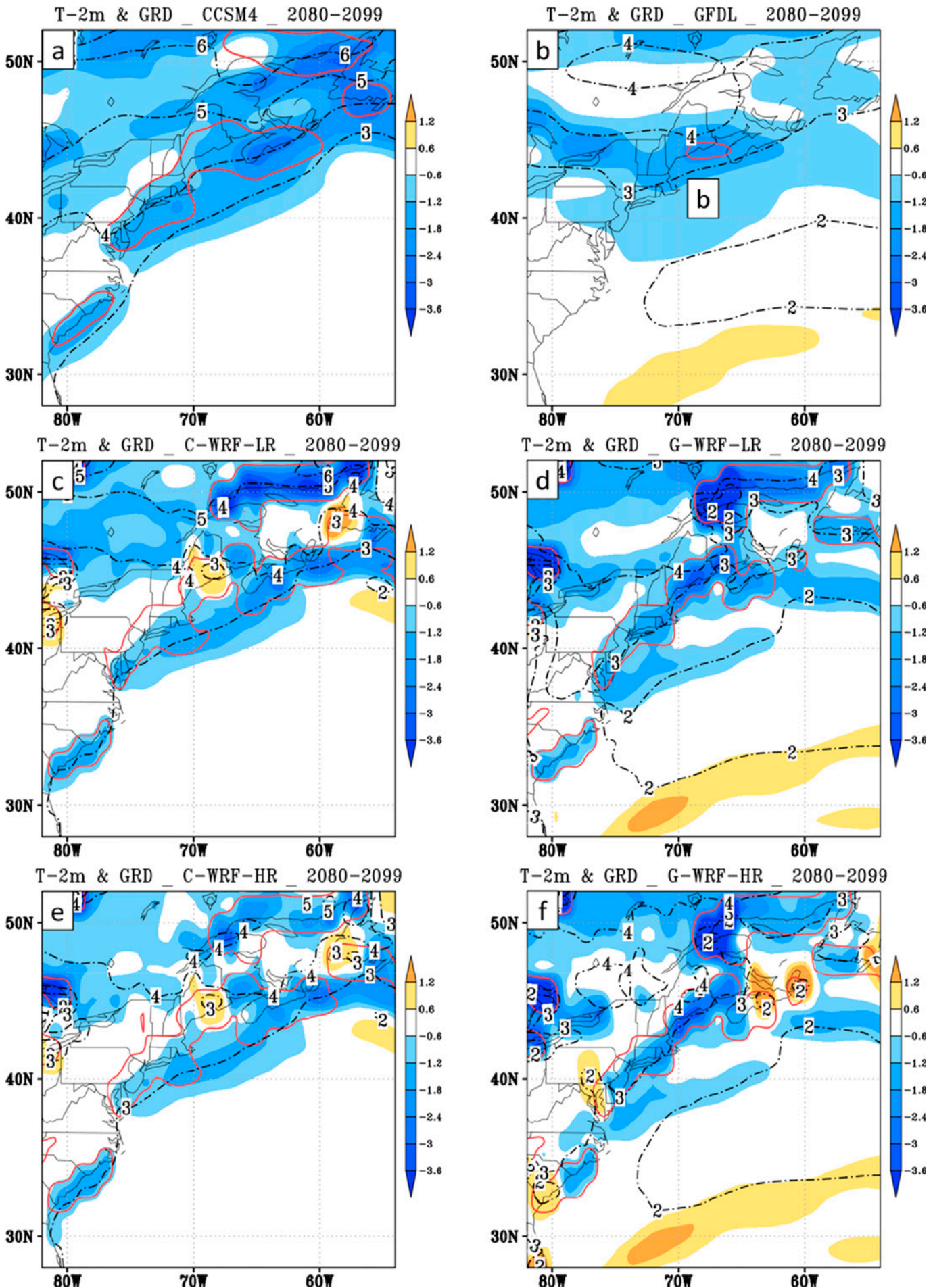

FIG. 12. The future change in surface temperature (dashed contours every $1 \mathrm{~K}$ ) and surface temperature gradient [color fill; $\mathrm{K}(1000 \mathrm{~km})^{-1}$ ], with the red lines highlighting regions of strong surface temperature gradient [ $>12 \mathrm{~K}$ $(1000 \mathrm{~km})^{-1}$ ] for the historical winters for (a) CCSM4, (b) GFDL, (c) C-WRF-LR, (d) G-WRF-LR, (e) C-WRF-HR, and (f) G-WRF-HR. 

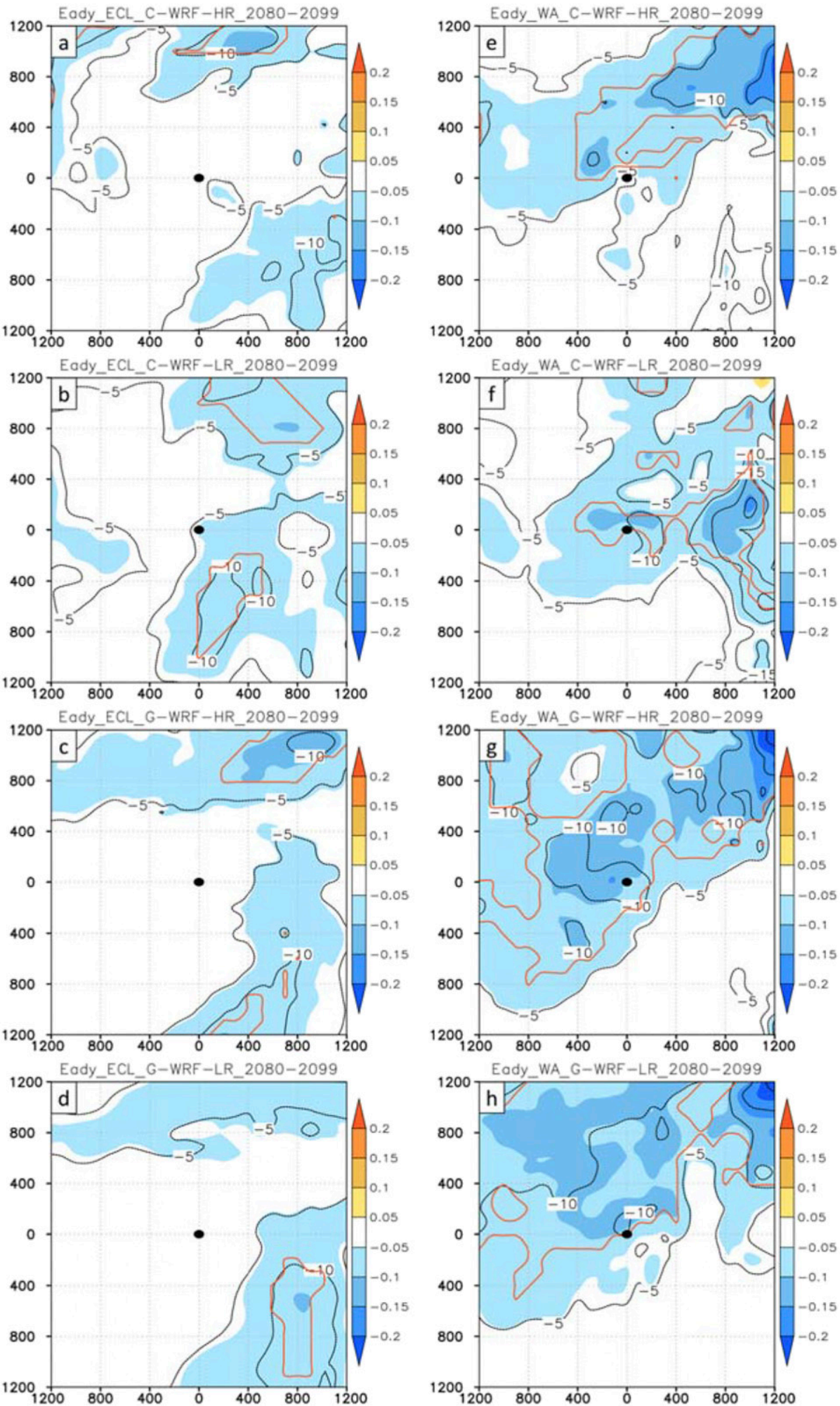

FIG. 13. The future change in $850-500-\mathrm{hPa}$ Eady growth rate (color fill; day $^{-1}$, with percent change contoured every $5 \%$ ) composited around the cyclone centers within the ECL region for (a) C-WRF-HR, (b) C-WRF-LR, (c) G-WRF-HR, and (d) G-WRF-LR. The black dot is the position of cyclone center. (e)-(h) As in (a)-(d), but for the cyclone centers within the WA region. Regions of statistically significant change at the $95 \%$ confidence level are contoured in red. 

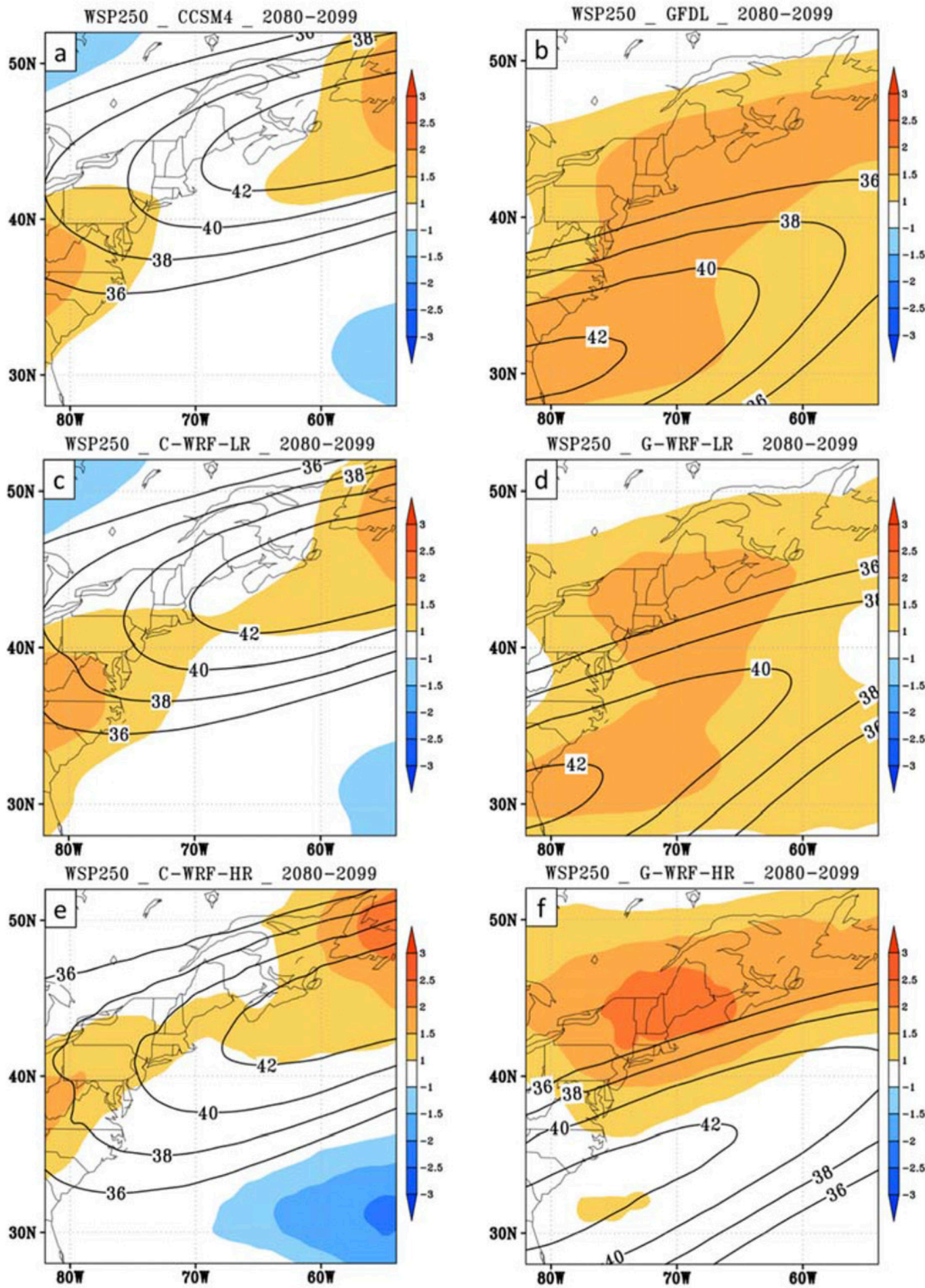

FIG. 14. The future change in 250-hPa wind speed (color filled; $\mathrm{m} \mathrm{s}^{-1}$, with contours showing the historical mean 250-hPa wind speed every $2 \mathrm{~m} \mathrm{~s}^{-1}$ ) for (a) CCSM4, (b) GFDL, (c) C-WRF-LR, (d) G-WRF-LR, (e) C-WRF-HR, and (f) G-WRF-HR. 
there is large regional variability (Figs. 15a,c,e). The increase over the land $(20 \%-40 \%)$ is larger than the increase over the WA region $(0 \%-20 \%)$. The maximum increase of precipitation $(30 \%-40 \%)$ is located along the ECL region, and C-WRF-HR has the largest increase over this region. The increase of precipitation rate $(10 \%-20 \%)$ along the coast in the GFDL group is smaller than the CCSM4 group, and over the ocean at the lower latitudes $\left(<40^{\circ} \mathrm{N}\right)$ the precipitation decreases by $5 \%-20 \%$ in the GFDL group while it increases by $0 \%-20 \%$ in the CCSM4 group (Figs. 15b,d,f).

The different precipitation changes in the future between models are mainly associated with different future changes in moisture content and static stability. To examine the future changes of moisture associated with the cyclones, the integrated moisture content from 950 to $250 \mathrm{hPa}$ around the cyclone center was composited (Fig. 16), which illustrates a significant increase $(95 \%$ confidence level) everywhere. Over the warm sector of the ECL cyclone centers, the moisture content increases by $25 \%-35 \%$ in the C-WRF runs (Figs. 16a,b) and $20 \%-$ $25 \%$ in the G-WRF runs (Figs. 16c,d). Over the warm sector of the WA cyclone centers, the moisture content increase in both the C-WRF $(20 \%-25 \%)$ and G-WRF $(5 \%-15 \%)$ runs (Figs. $16 \mathrm{e}-\mathrm{h})$ is less than the ECL cyclone centers. Around the ECL cyclone centers the moist static stability decreases by $5 \%-10 \%$ (95\% confidence level) in the C-WRF runs and increases by about $5 \%$ (not significant) in the G-WRF runs (not shown). The weaker (greater) static stability in the CCSM4 (GFDL) group favors more (less) precipitation. Meanwhile, the stronger upper-level forcing (Figs. 6 and 7) in the CCSM4 group than the GFDL group may also favor more precipitation in the CCSM4 group, although the upperlevel forcing does not have significant future changes in the two groups, respectively (Fig. 14).

The large difference in the cyclone-relative precipitation rate results in large differences in DPV from latent heating. In C-WRF-HR, there is a significant increase $(5 \%-20 \%)$ in DPV at the $95 \%$ confidence level over the comma head of the cyclone within the ECL region (Fig. 17a). Meanwhile, in C-WRF-LR the DPV increase $(5 \%-10 \%)$ is much weaker around the cyclone center (Fig. 17b). This may be one important reason for the $20 \%$ increase in the frequency of the strong cyclone $(<975 \mathrm{hPa})$ within the ECL region in C-WRF-HR but not in C-WRF-LR. It also suggests that the model resolution has a large impact on the future change of DPV in the WRF runs forced by CCSM4. In G-WRF-LR and G-WRF-HR, there are some weak increases in the DPV and far away from the cyclone center in the ECL region (Figs. 17c,d). The DPV increase in G-WRF-HR is not as large as C-WRF-HR because the precipitation increase is smaller as discussed above. In the composite DPV for the cyclone centers within the WA region, there are weak $(5 \%-10 \%)$ increases around the cyclone center in the WRF runs forced by CCSM4 and the situation is almost neutral in the WRF runs forced by GFDL (Figs. 17e-h), which is consistent with the cyclone-relative precipitation changes over the WA region.

\section{c. Future change in extreme cyclones in C-WRF-HR}

The strong cyclones $(<975 \mathrm{hPa})$ exhibit a $20 \%$ increase over the ECL region in C-WRF-HR but not in C-WRF-LR (Fig. 10c). To investigate the physical processes associated with the increase of the strong cyclones in C-WRF-HR and the difference between C-WRF-HR and C-WRF-LR further, we selected the extreme cyclone cases within the ECL region and examined the evolution of these cases in both C-WRF-HR and C-WRF-LR. The extreme cyclones are defined as the 95th percentile for each simulation and period within the ECL region $(<976.7 / 976.0 \mathrm{hPa}$ for C-WRF-HR historical/future period and $<980.3 / 979.8 \mathrm{hPa}$ for C-WRF-LR historical/future period). Figures 18 and 19 show the time series of the average related fields from the deepest cyclone center within the ECL region backward to $36 \mathrm{~h}$ before the deepest point.

The composite cyclone for the future period is weaker than the historical period at $-36 \mathrm{~h}(36 \mathrm{~h}$ before the deepest point within the ECL region) in both C-WRFHR and C-WRF-LR (Fig. 18a). However, the cyclone subsequently deepens more quickly in the future runs, especially in C-WRF-HR. In C-WRF-HR, the future cyclone is more intense than the historical cyclone after $-12 \mathrm{~h}$, and it is $\sim 4.5 \mathrm{hPa}$ deeper at peak intensity than the historical cyclone within the ECL region. That difference of cyclone central SLP at -6 and $0 \mathrm{~h}$ is statistically significant at the $95 \%$ confidence level. In C-WRF-LR, the cyclone is slightly deeper (by $\sim 0.5 \mathrm{hPa}$ ) in the future period at the deepest point, but the difference is not statistically significant. The mean $850-\mathrm{hPa}$ wind speed around the cyclone center has a similar change, with the C-WRF-HR winds about $10 \%$ stronger in the future period during the $12 \mathrm{~h}$ just before the deepest cyclone center (Fig. 18b). Meanwhile, the mean precipitation becomes $5 \%-32 \%$ greater in C-WRF-HR starting from $-24 \mathrm{~h}$ (Fig. 18c). Consistent with the precipitation, the mean DPV around the ECL extreme cyclone center is stronger starting from $-24 \mathrm{~h}$ in C-WRF-HR (Fig. 19b). The DPV difference from -12 to $0 \mathrm{~h}$ is statistically significant at the $95 \%$ confidence level. In C-WRF-LR the DPV also becomes stronger, but the increase is much smaller than in C-WRF-HR. During the same time, the surface temperature gradient in the future period is always significantly weaker than in the historical in both 

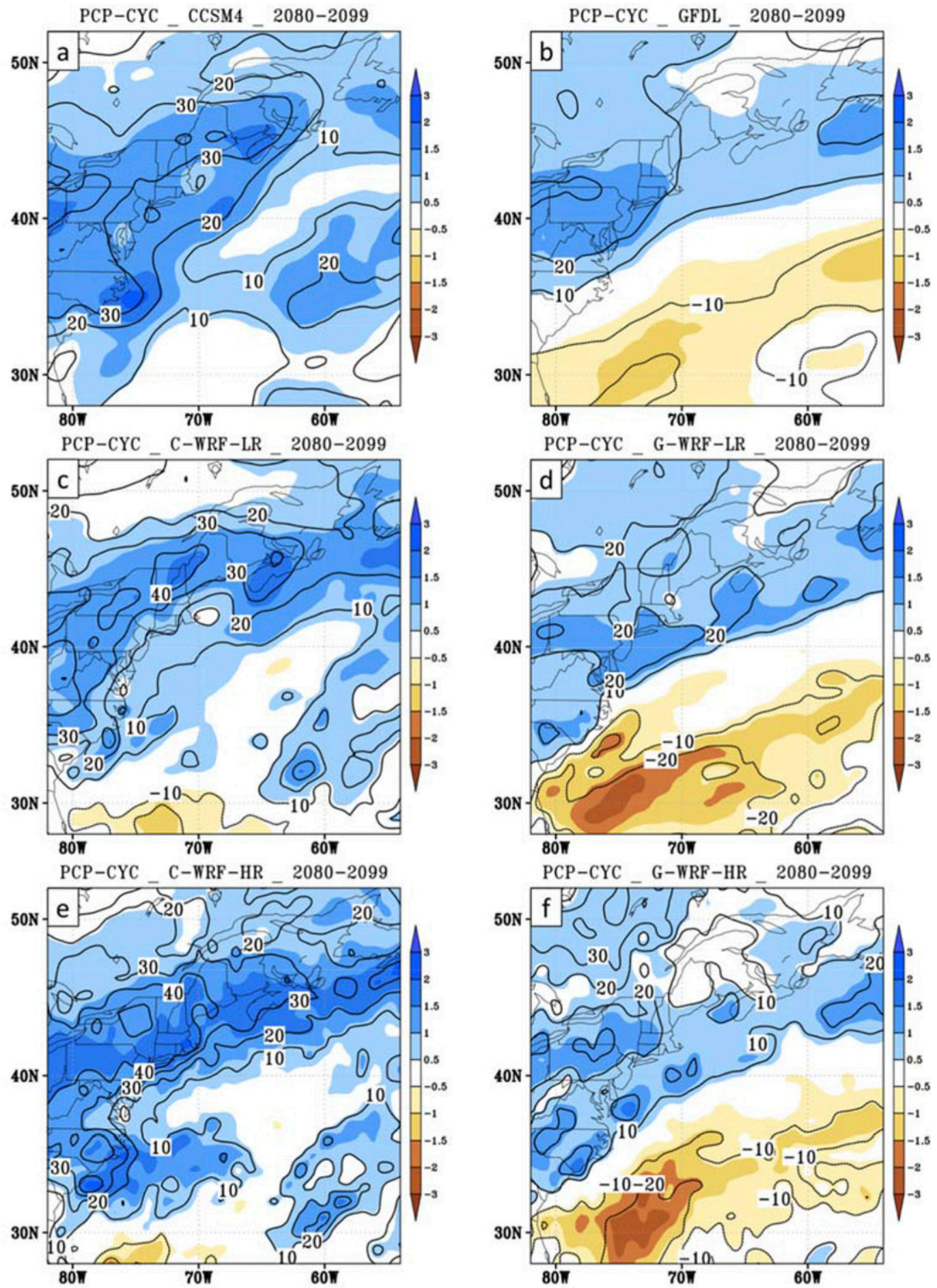

FIG. 15. The future change in cyclone-relative precipitation rate (color filled; $\mathrm{mm} \mathrm{day}^{-1}$, with contours showing the percentage change every 10\%) for (a) CCSM4, (b) GFDL, (c) C-WRF-LR, (d) G-WRF-LR, (e) C-WRF-HR, and (f) G-WRF-HR. 

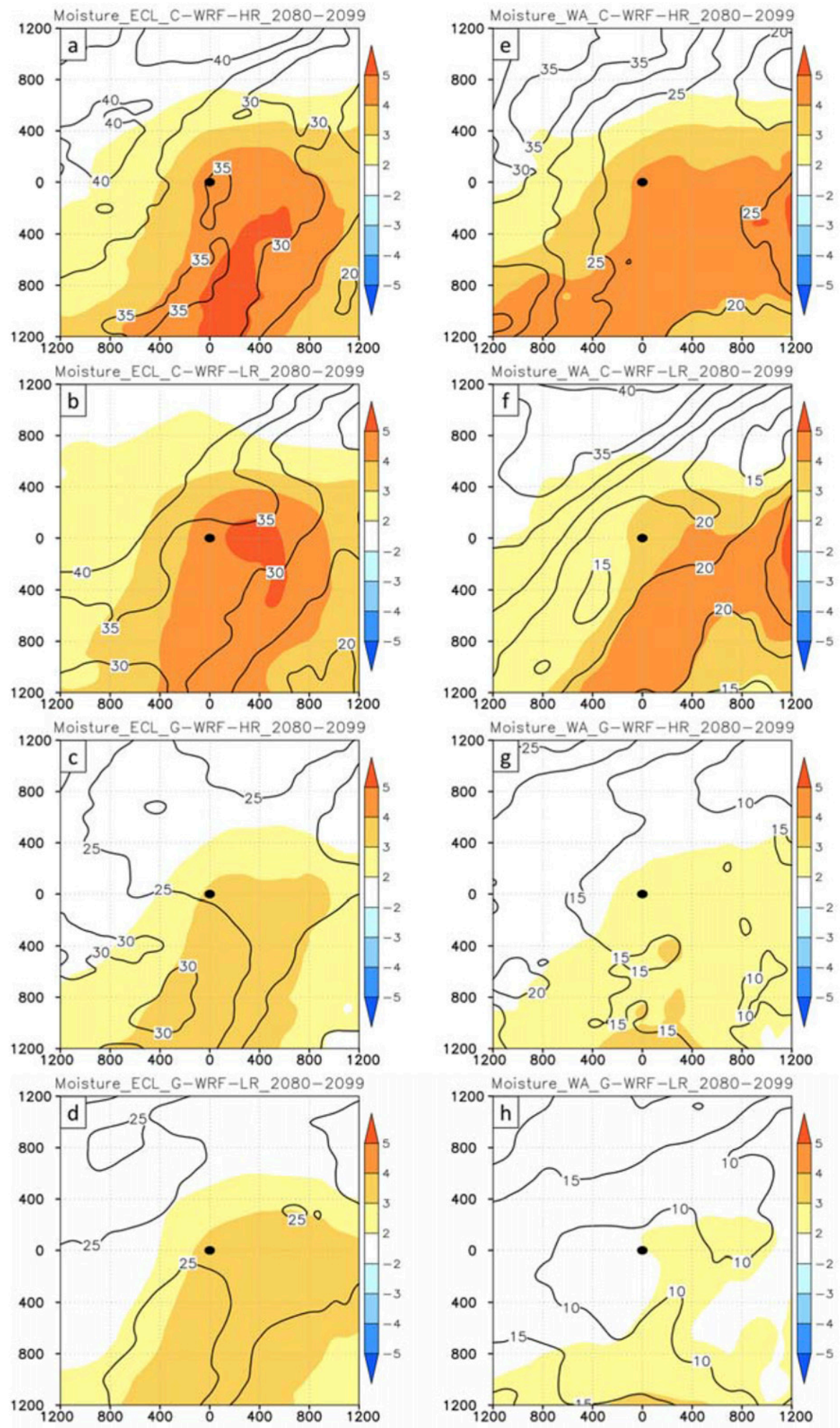

FIG. 16. As in Fig. 13, but for the 950-250-hPa moisture content (colors; $\mathrm{kg} \mathrm{m}^{-2}$ ). 

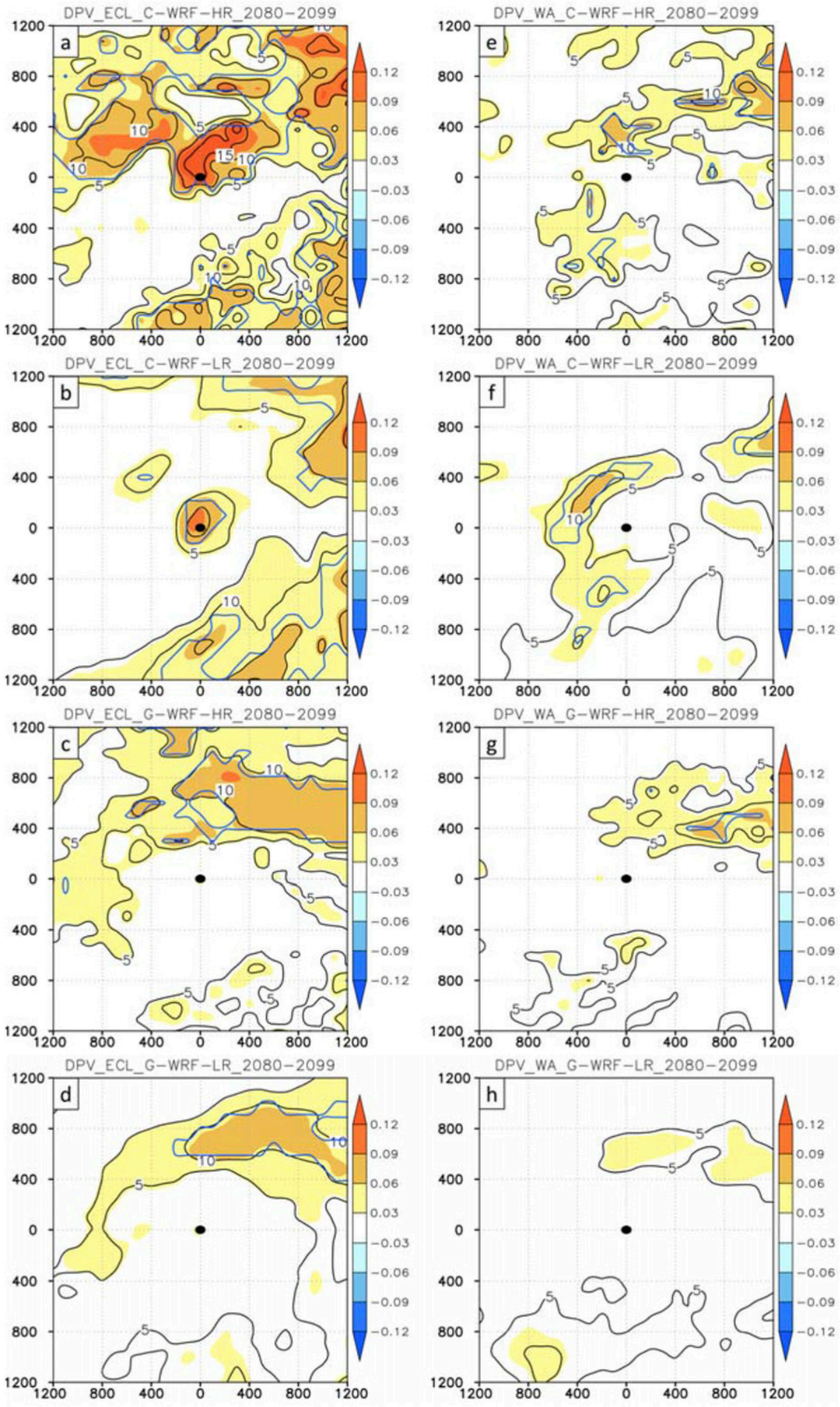

FIG. 17. As in Fig. 13, but for the DPV (colors; PVU). Regions of statistically significant change at the $95 \%$ confidence level are contoured in blue. 

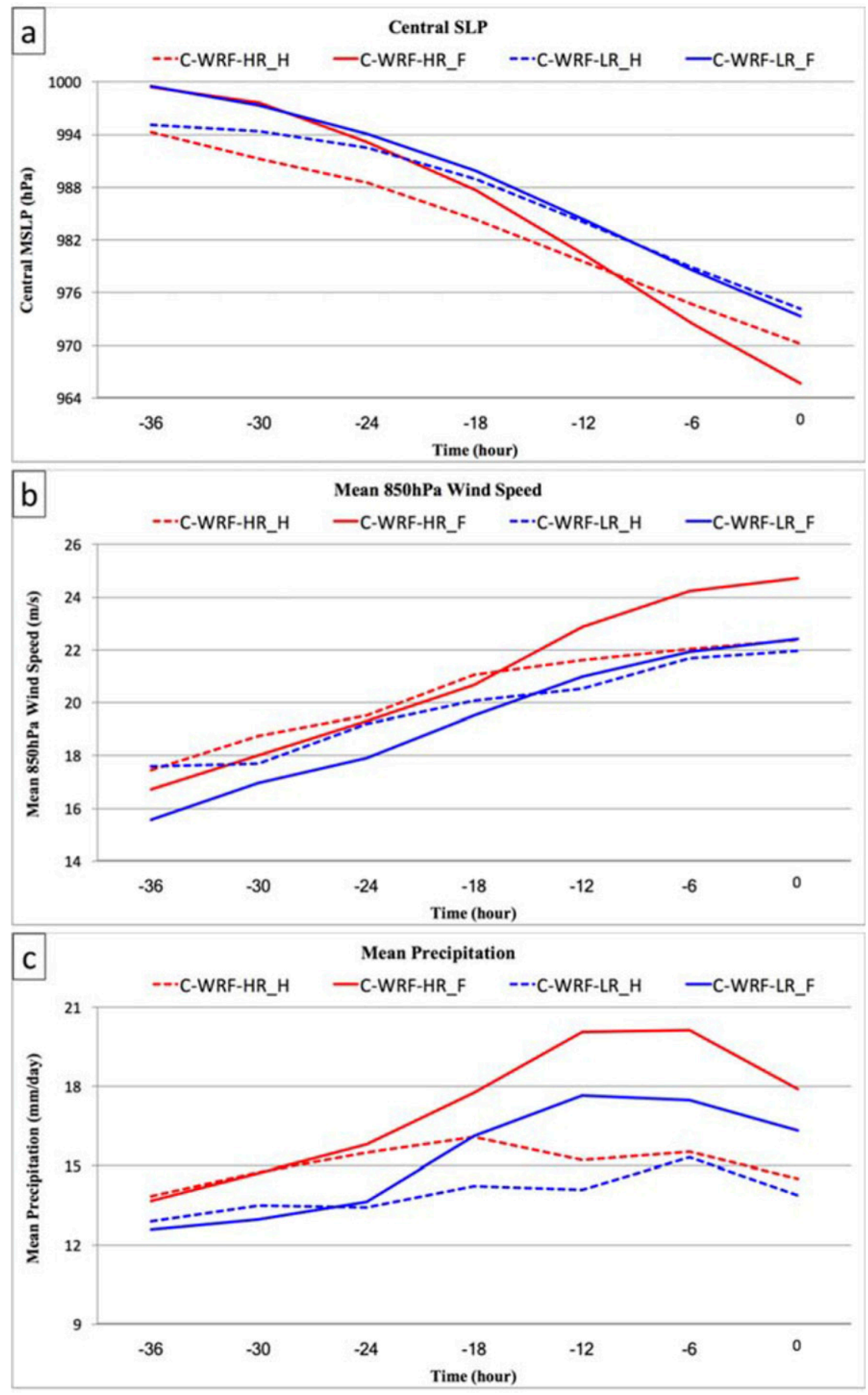

FIG. 18. Time series of (a) cyclone central SLP (hPa), (b) mean 850-hPa wind speed ( $\mathrm{m} \mathrm{s}^{-1}$ ), and $(\mathrm{c})$ mean precipitation rate $\left(\mathrm{mm} \mathrm{day}^{-1}\right)$ around the cyclone center of the extreme deep (95th percentile) cyclones within the ECL region, from the deepest cyclone center within the ECL region (hour 0 ) backward to $36 \mathrm{~h}$ before that deepest point (hour -36 ). The red lines are C-WRF-HR, and the blue lines are C-WRF-LR. The dashed lines are for the historical winters, and the solid lines are for the future winters. 


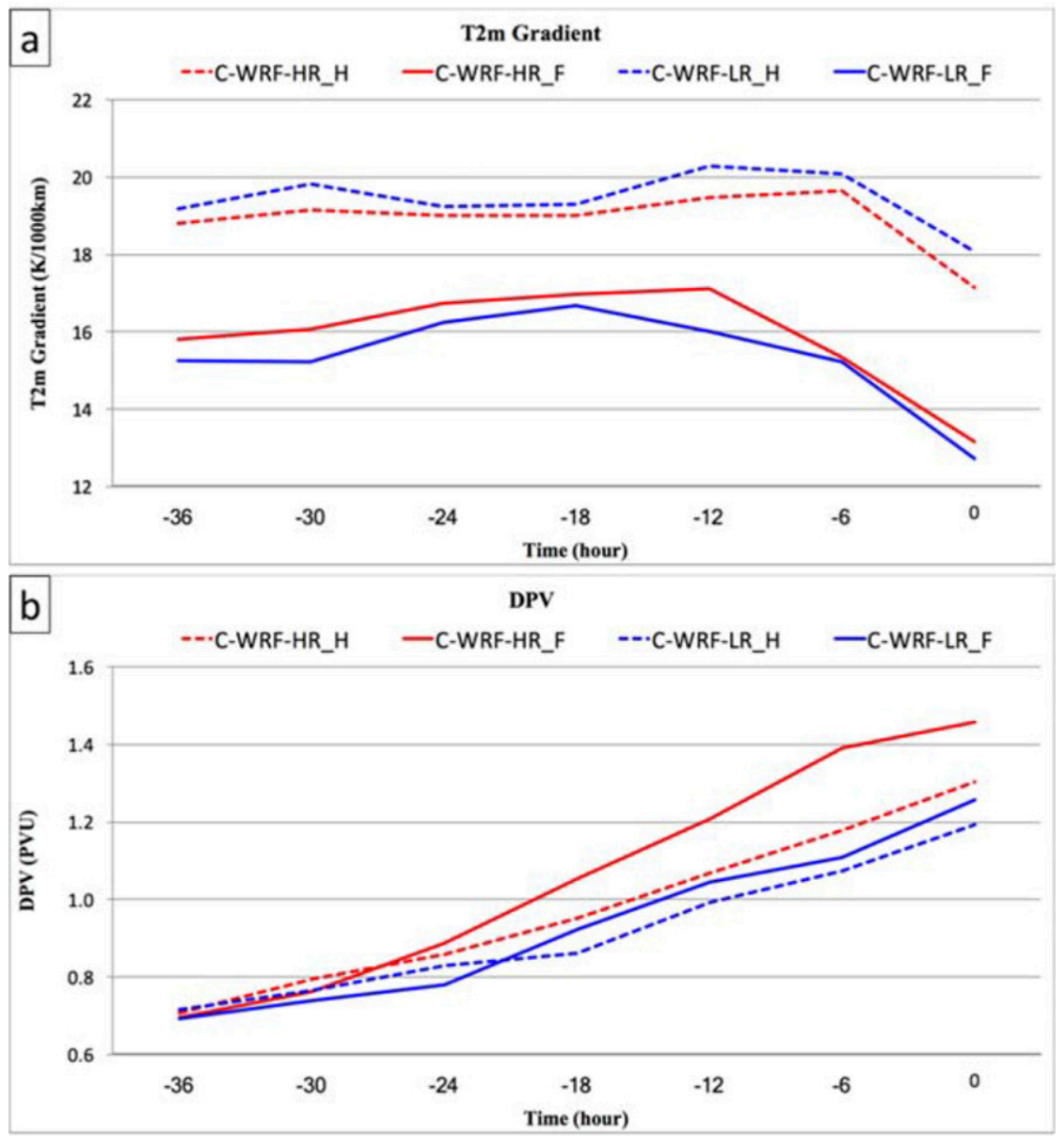

FIG. 19. As in Fig. 18, but for mean (a) surface temperature gradient $\left[\mathrm{K}(1000 \mathrm{~km})^{-1}\right]$ and (b) DPV (PVU).

C-WRF-HR and C-WRF-LR (Fig. 19a). The Eady growth rate around those cyclone centers has weak insignificant decreases $(\sim 5 \%)$ before $-18 \mathrm{~h}$ and nearly no change after $-18 \mathrm{~h}$ (not shown).

G-WRF-HR and G-WRF-LR have a $25 \%-30 \%$ decrease in the deep cyclones (Figs. 10b,d) in the ECL region, due to the pronounced decrease in low-level temperature gradient $(5 \%-20 \%)$ and relatively small changes in the other factors. A weak increase $(5 \%-$ $10 \%$ ) in DPV in the G-WRF runs exists at $300-1000 \mathrm{~km}$ northeast from the cyclone center (Figs. 17c,d), but this increase was not large enough to overcome the decrease in baroclinicity.

\section{Conclusions}

This study uses a regional model (WRF) to dynamically downscale historical and future (RCP8.5) simulations from two different CMIP5 GCMs: CCSM4 and GFDL-ESM2M. The area of interest is the winter storm track over eastern North America and the western Atlantic. Six-hourly GCM output is used to create initial and boundary conditions directly for both of the highresolution $\left(0.2^{\circ}\right.$; WRF-HR) and low-resolution $\left(1.0^{\circ}\right.$; WRF-LR) simulations for 20 historical and 20 future winters.

When compared with the CFSR analysis during the historical period, the GCMs, but especially GFDL, have a relatively large underprediction bias in both cyclone frequency and intensity. High-resolution dynamical downscaling reduces some of the bias, especially for the cyclone intensity. In the large ECWA region, CCSM4 underestimates the total number of cyclones by $\sim 14 \%$ and the rapid deepening cases by $\sim 30 \%$ (Figs. 2-5) with respect to CFSR, and the cyclone intensity tends to be too weak $(\sim 3.8 \mathrm{hPa}$ for the mean central SLP of all cyclone centers). The cyclone properties in C-WRF-LR are very similar to CCSM4 given the similar resolutions. However, C-WRF-HR reduces the underprediction in rapid deepening cases from $\sim 30 \%$ to $\sim 15 \%$, 
but it still underestimates the total number of cyclones by about $15 \%$. Thus, the greater resolution improves cyclone intensity, but the frequency of storms is still controlled by the parent CCSM4 given the boundary constraints of CCSM4. There is only a small difference in surface temperature gradient, Eady growth rate, and the upper-level jet, with increased resolution, while the $10 \%-15 \%$ stronger low-level $(900-750 \mathrm{hPa})$ diabatic potential vorticity (DPV) from latent heat release is the key factor to the deeper cyclones in C-WRF-HR (Figs. 6, 7, and 8). GFDL also underestimates the total number of cyclones by $\sim 26 \%$ and the rapid deepening cases by $\sim 60 \%$ with respect to CFSR (Figs. 3 and 5), during the historical period. The historical surface temperature gradient in GFDL is too weak ( $30 \%-50 \%$ weaker than CFSR). GWRF-LR and G-WRF-HR can greatly enhance the surface temperature gradient and reduce the underprediction of total cyclone number from $26 \%$ in GFDL to $18 \%$ and $12 \%$, respectively. Meanwhile, G-WRFHR has more rapid deepening cases and deep cyclones as a result of stronger latent heat release and slightly stronger Eady growth rate and upper-level jet relative to G-WRF-LR (Figs. 7 and 8).

There is a large difference in the future change of CCSM4 and GFDL cyclones along the east coast of North America (Figs. 9, 10, and 11). CCSM4 has an increase $(10 \%-30 \%)$ in cyclone frequency along the coast and some decreases $(10 \%-20 \%)$ over the ocean, which is similar to the mean change of the seven best CMIP5 GCMs in Colle et al. (2013). Meanwhile, GFDL has a decrease $(10 \%-30 \%)$ over most regions, especially over the ocean, which is similar to the mean change of the seven worst CMIP5 GCMs in Colle et al. (2013). Generally, the future cyclone changes in WRF are constrained by the corresponding GCM given the regional nesting approach. WRF forced by CCSM4 has an increase in cyclone track density and rapid deepening cases along the East Coast, whereas WRF forced by GFDL decreases over most regions. However, C-WRFHR has a $20 \%$ increase in the strong cyclones $(<975 \mathrm{hPa})$ and the rapid deepening cases [by more than $-5 \mathrm{hPa}$ $\left.(6 \mathrm{~h})^{-1}\right]$ in the ECL region. The dynamical downscaling of two GCMs for 20 historical and 20 future winters cannot provide a high confidence to predict the future changes of cyclone activity. However, the dynamical and physical reasons for the different model projections are critical to improve our understanding to the potential future changes of cyclone activity.

The reasons for the difference of future cyclone changes between the CCSM4 and GFDL groups are related to many factors. The future surface baroclinicity and Eady growth rate decreases along the east coast of North America in all models. The decrease of surface temperature gradient is concentrated more along the coast (the historical maximum region of surface temperature gradient) in the GFDL group and more offshore in the CCSM4 group (Fig. 12). The Eady growth rate exhibits a larger decrease in the WA region $(5 \%-$ $10 \%)$ than in the ECL region $(\sim 5 \%)$ in both of the CCSM4 and GFDL groups (Fig. 13). The upper-level PV (500-200 hPa) has a weak decrease (about -5\%) around the ECL region in the CCSM4 group but is nearly neutral in the GFDL group (not shown). The upper-level jet $(250 \mathrm{hPa})$ becomes slightly stronger in the jet core just along the east coast of North America in the CCSM4 group and a slight northward shift in the GFDL group (Fig. 14). These differences contribute to the different future cyclone changes but likely cannot explain the large difference near the coast.

The different changes of latent heat release due to different precipitation changes play an important role in the different future cyclone changes. The stronger latent heat release from heavier precipitation $(20 \%-40 \%)$ in the future over the East Coast region is favorable to the cyclone developing in the CCSM4 group, while the latent heat release from heavier precipitation $(5 \%-25 \%)$ is relatively weaker in the GFDL group (Figs. 15 and 17). The difference in precipitation change is mainly related to the different low-level temperature change (thus moisture), moist static stability change as described in Zhang and Colle (2017), and upper-level forcing change discussed above. The moisture content increase around the cyclone center in the CCSM4 group is about $5 \%-10 \%$ larger than that in the GFDL group, and the increase in the ECL region is about 5\%-15\% larger than that in the WA region (Fig. 16). Meanwhile, the atmosphere is less stable at the high latitudes over the continent and more stable over the ocean at midlatitudes (Zhang and Colle 2017). The poleward expansion of subtropical dry zones (Scheff and Frierson 2012) explains the neutral or negative changes in precipitation in the WA region. In addition to the other factors discussed in the last paragraph, these differences in the precipitation and latent heat release also contribute to the large difference of cyclone changes near the coast between the CCSM4 and GFDL groups, as well as the difference between the ECL and WA region.

The future changes of cyclone frequency and location in WRF are constrained by the corresponding GCM, and the difference in these changes between the two GCMs is not reduced much after dynamical downscaling (Figs. 9, 10, and 11), implying that the overall change of cyclone frequency and location is dominated by changes in the large-scale flow and forcing. Some studies (Marciano et al. 2015; Willison et al. 2015; Michaelis et al. 2017) using the pseudo-global warming approach to investigate 
the future changes of extratropical cyclones may neglect a large part of the variability among models, because the PGW approach only adds the thermal changes in the future simulation but does not include large-scale dynamical changes. On the other hand, the model resolution has a great impact on some of the precipitation processes and cyclone intensity. C-WRF-HR has an increase in the strong $(<975 \mathrm{hPa})$ cyclones in the ECL region, while C-WRF-LR does not have such an increase. In the future period, the baroclinicity is persistently weaker than the historical, and the mean intensity of extreme cyclones ( $95 \%$ percentile) in the ECL region is weaker than the historical at the early stage in both C-WRF-HR and C-WRF-LR (Figs. 18 and 19). However, those extreme cyclones exhibit an enhanced positive feedback between the latent heat release from precipitation and the cyclone deepening given more moisture in a warmer climate and produces even more extreme deep cyclones in C-WRF-HR. That does not occur in C-WRF-LR, suggesting that the diabatic process is sensitive to the model horizontal resolution. Over the WA region there is no such an increase in extreme cyclones in both C-WRF-HR and C-WRF-LR due to the smaller increase in latent heat release and larger decrease in Eady growth rate as discussed above.

The projected decreases in the frequency of extratropical cyclones in the North Atlantic storm track are widely recognized in many GCMs. However, the regional future changes of the intense cyclones may be ignored, especially since these coarse-resolution GCMs have limitations in simulating the intense cyclones. Our results suggest that caution is warranted when interpreting the future changes of intense cyclones along the east coast of North America in GCMs, which has implications for other cyclone impact studies, such as storm surge (Roberts et al. 2017) and precipitation (Zhang and Colle 2017). Future research should also involve global high-resolution WRF experiments, which can prevent boundary constraints. Downscaling more GCM members is necessary to assess the model diversity in future climate change.

Acknowledgments. We thank the three reviewers for their valuable comments, which helped to improve our manuscript. We acknowledge the World Climate Research Program Working Group on Coupled Modeling, which is responsible for CMIP. We thank Dr. Kevin Hodges for use of his TRACK software. The authors acknowledge the support of the NOAA Climate Program Office Modeling, Analysis, Predictions and Projections (MAPP) Program (NA11OAR4310104) as well as support from the U.S. Army Corps of Engineers

(USACE) Climate Preparedness and Resilience Program with administrative support from Oak Ridge Institute for Science and Education (ORISE).

\section{APPENDIX}

\section{Acronyms and Abbreviations}

CCSM4

CMIP5

C-WRF

C-WRF-HR

C-WRF-LR

DPV

ECL

ECW

ECWA

GCM

GFDL (GFDL-

ESM2M)

G-WRF

G-WRF-HR

G-WRF-LR

$\mathrm{RCP} 8.5$

SLP

SST

WA

WRF-HR

WRF-LR

WRF
NCAR Community Climate System Model, version 4

Coupled Model Intercomparison Project, phase 5

WRF forced by CCSM4

High-resolution $\left(0.2^{\circ}\right)$ WRF forced by CCSM 4

Low-resolution $\left(1.0^{\circ}\right)$ WRF forced by CCSM4

Diabatic potential vorticity

East coast land

East coast water

East coast and western Atlantic

General circulation model

Geophysical Fluid Dynamics Laboratory Earth System Model with MOM, version 4, component

WRF forced by GFDL-ESM2M

High-resolution $\left(0.2^{\circ}\right) \mathrm{WRF}$ forced by GFDL-ESM2M

Low-resolution $\left(1.0^{\circ}\right) \mathrm{WRF}$ forced by GFDL-ESM2M

Representative concentration pathway 8.5

Sea level pressure

Sea surface temperature

Western Atlantic

High-resolution $\left(0.2^{\circ}\right) \mathrm{WRF}$

Low-resolution $\left(1.0^{\circ}\right) \mathrm{WRF}$

Weather Research and Forecasting Model

\section{REFERENCES}

Bengtsson, L., K. I. Hodges, and E. Roeckner, 2006: Storm tracks and climate change. J. Climate, 19, 3518-3543, https://doi.org/ 10.1175/JCLI3815.1.

Booth, J., C. Naud, and J. Willison, 2018: Evaluation of extratropical cyclone precipitation in the North Atlantic Basin: An analysis of ERA-Interim, WRF, and two CMIP5 models. J. Climate, 31, 2345-2360, https://doi.org/10.1175/ JCLI-D-17-0308.1.

Catalano, A. J., and A. J. Broccoli, 2018: Synoptic characteristics of surge-producing extratropical cyclones along the northeast coast of the United States. J. Appl. Meteor. Climatol., 57, 171184, https://doi.org/10.1175/JAMC-D-17-0123.1. 
Champion, A. J., K. I. Hodges, L. O. Bengtsson, N. S. Keenlyside, and M. Esch, 2011: Impact of increasing resolution and a warmer climate on extreme weather from Northern Hemisphere extratropical cyclones. Tellus, 63A, 893-906, https:// doi.org/10.1111/j.1600-0870.2011.00538.x.

Chang, E. K., 2013: CMIP5 projection of significant reduction in extratropical cyclone activity over North America. J. Climate, 26, 9903-9922, https://doi.org/10.1175/JCLI-D-13-00209.1.

__ 2014: Impacts of background field removal on CMIP5 projected changes in Pacific winter cyclone activity. J. Geophys. Res. Atmos., 119, 4626-4639, https://doi.org/10.1002/ 2013JD020746.

_ Y. Yuo, X. Xia, and M. Zheng, 2013: Storm-track activity in IPCC AR4/CMIP3 model simulations. J. Climate, 26, 246-260, https://doi.org/10.1175/JCLI-D-11-00707.1.

Chou, M. D., and M. J. Suarez, 1999: A solar radiation parameterization (CLIRAD-SW) for atmospheric studies. NASA Tech. Memo. NASA/TM-1999-104606, Vol. 15, 51 pp., https:// gmao.gsfc.nasa.gov/pubs/docs/Chou136.pdf.

- — - X. Z. Liang, M. M. H. Yan, and C. Cote, 2001: A thermal infrared radiation parameterization for atmospheric studies. NASA Tech. Memo. NASA/TM-2001-104606, Vol. 19, 68 pp., https://ntrs.nasa.gov/archive/nasa/casi.ntrs.nasa.gov/ 20010072848.pdf.

Colle, B. A., 2003: Numerical simulations of the extratropical transition of Floyd (1999): Structural evolution and responsible mechanisms for the heavy rainfall over the northeast United States. Mon. Wea. Rev., 131, 2905-2926, https://doi.org/10.1175/ 1520-0493(2003)131<2905:NSOTET>2.0.CO;2.

, F. Buonaiuto, M. J. Bowman, R. E. Wilson, R. Flood, R. Hunter, A. Mintz, and D. Hill, 2008: New York City's vulnerability to coastal flooding. Bull. Amer. Meteor. Soc., 89, 829-842, https://doi.org/10.1175/2007BAMS2401.1.

_, K. Rojowsky, and F. Buonaiuto, 2010: New York City storm surges: Climatology and analysis of the wind and cyclone evolution. J. Appl. Meteor. Climatol., 49, 85-100, https://doi.org/ 10.1175/2009JAMC2189.1.

_- Z. Zhang, K. A. Lombardo, E. Chang, P. Liu, and M. Zhang, 2013: Historical evaluation and future prediction of eastern North American and western Atlantic extratropical cyclones in the CMIP5 models during the cool season. J. Climate, 26, 6882-6903, https://doi.org/10.1175/JCLI-D-12-00498.1.

Diaconis, P., and B. Efron, 1983: Computer-intensive methods in statistics. Sci. Amer., 248, 116-131, https://doi.org/10.1038/ scientificamerican0583-116.

Donner, L. J., and Coauthors, 2011: The dynamical core, physical parameterizations, and basic simulation characteristics of the atmospheric component AM3 of the GFDL global coupled model CM3. J. Climate, 24, 3484-3519, https://doi.org/10.1175/ 2011JCLI3955.1.

Field, P. R., and R. Wood, 2007: Precipitation and cloud structure in midlatitude cyclones. J. Climate, 20, 233-254, https:// doi.org/10.1175/JCLI3998.1.

Geng, Q., and M. Sugi, 2003: Possible change of extratropical cyclone activity due to enhanced greenhouse gases and sulfate aerosols-Study with a high-resolution AGCM. J. Climate, 16, 2262-2274, https://doi.org/10.1175/1520-0442(2003)16<2262: PCOECA $>2.0 . \mathrm{CO} ; 2$.

Gent, P. R., and Coauthors, 2011: The Community Climate System Model version 4. J. Climate, 24, 4973-4991, https://doi.org/ 10.1175/2011JCLI4083.1.

Hodges, K. I., 1994: A general method for tracking analysis and its application to meteorological data. Mon. Wea. Rev., 122,
2573-2586, https://doi.org/10.1175/1520-0493(1994)122<2573: AGMFTA $>2.0 . \mathrm{CO} ; 2$.

- 1995: Feature tracking on the unit sphere. Mon. Wea. Rev., 123, 3458-3465, https://doi.org/10.1175/1520-0493(1995)123<3458: FTOTUS $>2.0 . \mathrm{CO} ; 2$.

Janjić, Z. I., 1994: The step-mountain eta coordinate model: Further developments of the convection, viscous sublayer, and turbulence closure schemes. Mon. Wea. Rev., 122 927-945, https://doi.org/10.1175/1520-0493(1994)122<0927: TSMECM $>2.0 . \mathrm{CO} ; 2$.

Jung, T., S. K. Gulev, I. Rudeva, and V. Soloviov, 2006: Sensitivity of extratropical cyclone characteristics to horizontal resolution in the ECMWF model. Quart. J. Roy. Meteor. Soc., 132, 1839-1857, https://doi.org/10.1256/qj.05.212.

Knox, J. A., J. D. Frye, J. D. Durkee, and C. M. Fuhrmann, 2011: Non-convective high winds associated with extratropical cyclones. Geogr. Compass, 5, 63-89, https://doi.org/10.1111/ j.1749-8198.2010.00395.x.

Lambert, S. J., and J. C. Fyfe, 2006: Changes in winter cyclone frequencies and strengths simulated in enhanced greenhouse warming experiments: Results from the models participating in the IPCC diagnostic exercise. Climate Dyn., 26, 713-728, https://doi.org/10.1007/s00382-006-0110-3.

Marciano, C. G., G. M. Lackmann, and W. A. Robinson, 2015: Changes in U.S. East Coast cyclone dynamics with climate change. J. Climate, 28, 468-484, https://doi.org/10.1175/JCLI-D-14-00418.1.

Meinshausen, M., and Coauthors, 2011: The RCP greenhouse gas concentrations and their extensions from 1765 to 2300 . Climatic Change, 109, 213, https://doi.org/10.1007/s10584-011-0156-z.

Michaelis, A. C., J. Willison, G. M. Lackmann, and W. A. Robinson, 2017: Changes in winter North Atlantic extratropical cyclones in high-resolution regional pseudo-global warming simulations. J. Climate, 30, 6905-6925, https:// doi.org/10.1175/JCLI-D-16-0697.1.

Mlawer, E. J., S. J. Taubman, P. D. Brown, M. J. Iacono, and S. A. Clough, 1997: Radiative transfer for inhomogeneous atmospheres: RRTM, a validated correlated- $k$ model for the longwave. J. Geophys. Res., 102, 16663-16682, https://doi.org/ 10.1029/97JD00237.

Morrison, H., G. Thompson, and V. Tatarskii, 2009: Impact of cloud microphysics on the development of trailing stratiform precipitation in a simulated squall line: Comparison of oneand two-moment schemes. Mon. Wea. Rev., 137, 991-1007, https://doi.org/10.1175/2008MWR2556.1.

Naud, C. M., D. J. Posselt, and S. C. Van Den Heever, 2012: Observational analysis of cloud and precipitation in midlatitude cyclones: Northern versus Southern Hemisphere warm fronts. J. Climate, 25, 5135-5151, https://doi.org/ 10.1175/JCLI-D-11-00569.1.

Neu, U., and Coauthors, 2013: IMILAST: A community effort to intercompare extratropical cyclone detection and tracking algorithms. Bull. Amer. Meteor. Soc., 94, 529-547, https:// doi.org/10.1175/BAMS-D-11-00154.1.

Orton, P. M., T. M. Hall, S. A. Talke, A. F. Blumberg, N. Georgas, and S. Vinogradov, 2016: A validated tropicalextratropical flood hazard assessment for New York Harbor. J. Geophys. Res. Oceans, 121, 8904-8929, https://doi.org/10.1002/ 2016JC011679.

Roberts, K. J., B. A. Colle, and N. Korfe, 2017: Impact of simulated twenty-first-century changes in extratropical cyclones on coastal flooding at the Battery, New York City. J. Appl. Meteor. Climatol., 56, 415-432, https://doi.org/ 10.1175/JAMC-D-16-0088.1. 
Saha, S., and Coauthors, 2010: The NCEP Climate Forecast System Reanalysis. Bull. Amer. Meteor. Soc., 91, 1015-1057, https:// doi.org/10.1175/2010BAMS3001.1.

Scheff, J., and D. M. Frierson, 2012: Robust future precipitation declines in CMIP5 largely reflect the poleward expansion of model subtropical dry zones. Geophys. Res. Lett., 39, L18704, https://doi.org/10.1029/2012GL052910.

Seiler, C., and F. W. Zwiers, 2016: How well do CMIP5 climate models reproduce explosive cyclones in the extratropics of the Northern Hemisphere? Climate Dyn., 46, 1241-1256, https:// doi.org/10.1007/s00382-015-2642-x.

$\longrightarrow,-$ K. I. Hodges, and J. F. Scinocca, 2018: How does dynamical downscaling affect model biases and future projections of explosive extratropical cyclones along North America's Atlantic coast? Climate Dyn., 50, 677-692, https://doi.org/10.1007/ s00382-017-3634-9.

Skamarock, W. C., and Coauthors, 2008: A description of the Advanced Research WRF version 3. NCAR Tech. Note NCAR/ TN-475+STR, 113 pp., https://doi.org/10.5065/D68S4MVH.

Sweet, W. V., and C. Zervas, 2011: Cool-season sea level anomalies and storm surges along the U.S. East Coast: Climatology and comparison with the 2009/10 El Niño. Mon. Wea. Rev., 139, 2290-2299, https://doi.org/10.1175/MWR-D-10-05043.1.

Tamarin-Brodsky, T., and Y. Kaspi, 2017: Enhanced poleward propagation of storms under climate change. Nat. Geosci., 10, 908-913, https://doi.org/10.1038/s41561-017-0001-8.

Taylor, K. E., R. J. Stouffer, and G. A. Meehl, 2012: An overview of CMIP5 and the experiment design. Bull. Amer. Meteor. Soc., 93, 485-498, https://doi.org/10.1175/BAMS-D-11-00094.1.

Tewari, M., and Coauthors, 2004: Implementation and verification of the unified NOAH land surface model in the WRF Model. 20th Conf. on Weather Analysis and Forecasting/16th Conf. on Numerical Weather Prediction, Seattle, WA, Amer. Meteor. Soc., 11-15.

Willison, J., W. A. Robinson, and G. M. Lackmann, 2013: The importance of resolving mesoscale latent heating in the North Atlantic storm track. J. Atmos. Sci., 70, 2234-2250, https:// doi.org/10.1175/JAS-D-12-0226.1.

- —, and — 2015: North Atlantic storm-track sensitivity to warming increases with model resolution. J. Climate, 28, 4513-4524, https://doi.org/10.1175/JCLI-D-14-00715.1.

Woollings, T., B. Hoskins, M. Blackburn, D. Hassell, and K. Hodges, 2010: Storm track sensitivity to sea surface temperatures resolution in a regional atmosphere model. Climate Dyn., 35, 341-353, https://doi.org/10.1007/s00382009-0554-3.

Zappa, G., L. C. Shaffrey, K. I. Hodges, P. G. Sansom, and D. B. Stephenson, 2013: A multimodel assessment of future projections of North Atlantic and European extratropical cyclones in the CMIP5 climate models. J. Climate, 26, 5846-5862, https://doi.org/10.1175/JCLI-D-12-00573.1.

Zhang, Z., and B. A. Colle, 2017: Changes in extratropical cyclone precipitation and associated processes during the twenty-first century over eastern North America and the western Atlantic using a cyclone-relative approach. J. Climate, 30, 8633-8656, https://doi.org/10.1175/JCLI-D16-0906.1.

Zheng, M., E. K. Chang, B. A. Colle, Y. Luo, and Y. Zhu, 2017: Applying fuzzy clustering to a multimodel ensemble for U.S. East Coast winter storms: Scenario identification and forecast verification. Wea. Forecasting, 32, 881-903, https://doi.org/ 10.1175/WAF-D-16-0112.1. 